\title{
Surface drifters in the German Bight: model validation considering windage and Stokes drift
}

\author{
Ulrich Callies $^{1}$, Nikolaus Groll ${ }^{1}$, Jochen Horstmann ${ }^{1}$, Hartmut Kapitza ${ }^{1}$, Holger Klein ${ }^{2}$, Silvia Maßmann ${ }^{2}$, and \\ Fabian Schwichtenberg ${ }^{2}$ \\ ${ }^{1}$ Institute of Coastal Research, Helmholtz-Zentrum Geesthacht, Max-Planck-Str. 1, 21502 Geesthacht, Germany \\ ${ }^{2}$ Federal Maritime and Hydrographic Agency (BSH), Bernhard-Nocht-Str. 78, 20359 Hamburg, Germany \\ Correspondence to: Ulrich Callies (ulrich.callies@hzg.de)
}

Received: 12 May 2017 - Discussion started: 24 May 2017

Revised: 9 August 2017 - Accepted: 14 August 2017 - Published: 26 September 2017

\begin{abstract}
Six surface drifters (drogued at about $1 \mathrm{~m}$ depth) deployed in the inner German Bight (North Sea) were tracked for between 9 and 54 days. Corresponding simulations were conducted offline based on surface currents from two independent models (BSHcmod and TRIM). Inclusion of a direct wind drag $(0.6 \%$ of $10 \mathrm{~m}$ wind) was needed for successful simulations based on BSHcmod currents archived for a $5 \mathrm{~m}$ depth surface layer. Adding $50 \%$ of surface Stokes drift simulated with a third-generation wave model (WAM) was tested as an alternative approach. Results resembled each other during most of the time. Successful simulations based on TRIM surface currents $(1 \mathrm{~m}$ depth) suggest that both approaches were mainly needed to compensate insufficient vertical resolution of hydrodynamic currents.

The study suggests that the main sources of simulation errors were inaccurate Eulerian currents and lacking representation of sub-grid-scale processes. Substantial model errors often occurred under low wind conditions. A lower limit of predictability (about $3-5 \mathrm{~km} \mathrm{day}^{-1}$ ) was estimated from two drifters that were initially spaced $20 \mathrm{~km}$ apart but converged quickly and diverged again after having stayed at a distance of $2 \mathrm{~km}$ or less for about 10 days. In most cases, errors in simulated $25 \mathrm{~h}$ drifter displacements were of similar order of magnitude.
\end{abstract}

\section{Introduction}

Lagrangian particle tracking is a natural choice when origins or destinations of drifting objects (or water bodies) need to be known. Such methods have been developed for a wide range of applications (see Mariano et al., 2002). Examples from oceanography are simulations of physical dispersion (Schönfeld, 1995; Sentchev and Korotenko, 2005), possibly augmented by specific source and sink terms (e.g. Puls et al., 1997). In ecosystem modelling, Lagrangian transport models have been employed to better understand the process of non-indigenous species invading an ecosystem (Brandt et al., 2008), the risk of toxic algae blooms (Havens et al., 2010) or larval transport and connectivity being crucial to spatial fishery management (e.g. Nicolle et al., 2013; Robins et al., 2013). Lagrangian transport simulations also provide a basis for more comprehensive individual-based models of fish recruitment (e.g. Daewel et al., 2015).

Obviously, the quality of Lagrangian drift simulations has a particularly high practical relevance in the context of emergency operations like search and rescue (Breivik et al., 2013) or organization of efficient combating of oil spills (Broström et al., 2011; Maßmann et al., 2014). Modelling of surface drifter trajectories is particularly challenging as many of the input factors needed are poorly known. Often drift properties of search objects can only be estimated (Breivik et al., 2013). The present study refers to a drifter experiment conducted in the inner German Bight (North Sea) during MayJuly 2015. Corresponding offline drift simulations based on archived currents from two different models were undertaken to assess the degree of uncertainty that must reasonably be expected in this region.

The surface drifters deployed are ideal in the sense that their exposure to a direct aerodynamic force from wind (leeway or windage; Breivik and Allen, 2008) seems negligible. However, also Eulerian surface currents used can be a ma- 
jor source of uncertainty (Hufnagl et al., 2017). The circulation model BSHcmod, which this study mainly focuses on, is run operationally. In cases of necessity, drifter simulations will be based on a regridded archived version of model predictions with near-surface currents representative of a $5 \mathrm{~m}$ deep top layer. Therefore, even for an ideal surface drifter, introducing a direct wind drag can be helpful as a means of compensating insufficient vertical resolution of hydrodynamic currents. The second hydrodynamic model employed in this study, TRIM, was set up with a $1 \mathrm{~m}$ deep top layer. Comparing drift simulations based on outputs from the two different models helps assess uncertainties possibly related to the vertical resolution of near-surface currents.

More complex impacts of winds on surface currents may be mediated via waves (Perrie et al., 2003; Ardhuin et al., 2009). Röhrs et al. (2012) found evidence that predictability of drift trajectories can be improved by the inclusion of numerical wave modelling. On the other hand, Stokes drift and other wave effects are often neglected in operational systems. According to Breivik and Allen (2008), the main reason for this is that wave processes are already taken into account by empirically tuned windage coefficients that summarize changes of an object's trajectory induced by combined impacts of both winds and waves. The situation can differ in near-shore regions, where wave refraction directs waveinduced transports towards the coast (Sobey and Barker, 1997).

A key objective of this study is checking whether explicit inclusion of Stokes drift calculated with a state-of-the-art wave model (WAM) improves drift simulations. Assessing the necessity to distinguish between effects of direct wind drag and Stokes drift is essential to avoid overparametrization. Waves and resulting Stokes drift were calculated using the wind forcing also employed for hydrodynamic simulations with TRIM. However, we did not explore effects of including wave-current interactions into hydrodynamic simulations (Staneva et al., 2017).

Horizontal grid resolutions of the two hydrodynamic data sets (900 m in BSHcmod and $1.6 \mathrm{~km}$ in TRIM) allow for a proper representation of mesoscale eddies in the region of interest. However, simulations may miss relevant sub-mesoscale processes. According to Kjellsson and Döös (2012) the underestimation of eddy kinetic energy by Eulerian flows is a common finding of many model validation studies. This deficiency could be fixed by a transition to an advection-diffusion equation, introducing an additional stochastic random walk term. In this context, specification of the proper eddy diffusivity as function of grid resolution poses a major problem. There are, however, also concerns regarding the simple theoretical concept. For the advectiondiffusion approach to be valid, a spectral gap should separate processes on the scale resolved from sub-grid-scale processes. Such a gap may often not exist (see, De Dominicis et al., 2012, for instance).
Garraffo et al. (2001) compared the statistics of drifter observations in the North Atlantic with those of drift simulations based on Eulerian velocities from a model with about $6 \mathrm{~km}$ horizontal resolution. Without a stochastic model of sub-grid-scale actions, they found simulations to underestimate eddy energy. Simulated absolute dispersion being too low was also reported by Kjellsson and Döös (2012) evaluating drifters deployed in the Baltic Sea. Referring to global ocean data, Döös et al. (2011) tuned random turbulent velocity in their drift model to achieve better agreement between relative dispersion of simulated trajectories and corresponding observations. However, they found this approach was too simple for a reasonable reproduction of Lagrangian properties.

More sophisticated analyses of the relative dispersion of pairs of particles try to distinguish the regimes of "local dispersion" driven by eddies comparable in size to the distance between two drifters and of "non-local dispersion" driven by eddies with scales much larger than this distance (e.g. Kosza$1 \mathrm{ka}$ et al., 2009). Beron-Vera and LaCasce (2016) conducted such an analysis for data from the Grand Lagrangian Deployment experiment (GLAD), in which more than 300 drifters were deployed in the Gulf of Mexico. Drifter launch positions spaced from $100 \mathrm{~m}$ to $15 \mathrm{~km}$ apart allowed to study submesoscale dispersion characteristics in great detail. However, referring to experimental data in the south-western Gulf of Mexico, Sansón et al. (2017) show that for large initial distances the probability density functions of pair separations get dependent on prevailing mesoscale circulation patterns. This aspect seems particularly relevant for the present study. Variations of the residual current regime in the inner German Bight can very well be approximated in terms of only 2-3 degrees of freedom, depending on prevailing winds (Callies et al., 2017). Tidal currents dominate short-term transports.

The data available for this study (six drifters, tracked between 9 and 54 days) are insufficient for studying features of oceanic turbulence. Therefore, in the present model validation study, stochastic simulation of sub-grid-scale processes will not be considered. Ohlmann et al. (2012) provide an example that even an accurate reproduction of mean drifter pair separation does not necessarily imply good agreement between observations and corresponding simulations. According to Coelho et al. (2015), models used in the aforementioned GLAD experiment in the Gulf of Mexico had limited success capturing the observed drift patterns. Barron et al. (2007) provide a list of typical separation rates in different regions worldwide. For an experiment in the Ria de Vigo estuary in north-west Spain, Huhn et al. (2012) reported simulation errors that were relatively small compared to those typically found in the open ocean. This study tries to provide a realistic estimate of how reliable operational forecasts in the German Bight, another shelf sea region, can be expected to be. This includes gaining preliminary indications for regions where the deterministic part of a model needs improvement. 
Table 1. Drifters deployed in May 2015.

\begin{tabular}{|c|c|c|c|c|c|c|c|c|c|c|}
\hline \multirow[t]{2}{*}{ No. } & \multirow[t]{2}{*}{ Type } & \multicolumn{3}{|c|}{ Start } & \multicolumn{3}{|c|}{ End } & \multirow{2}{*}{$\begin{array}{l}\text { Length } \\
(\mathrm{km})\end{array}$} & \multirow{2}{*}{$\begin{array}{l}\text { Dist } \\
(\mathrm{km})\end{array}$} & \multirow{2}{*}{$\begin{array}{r}\Delta T \\
\text { (days) }\end{array}$} \\
\hline & & Time (UTC) & ${ }^{\circ} \mathrm{E}$ & ${ }^{\circ} \mathrm{N}$ & Time (UTC) & ${ }^{\circ} \mathrm{E}$ & ${ }^{\circ} \mathrm{N}$ & & & \\
\hline 1 & MD03i & 19 May (12:31) & 7.5216 & 54.2160 & 2 Jun (21:12) & 8.8338 & 54.5180 & 1032.1 & 91.7 & 14.4 \\
\hline 2 & MD03i & 21 May (17:13) & 7.1484 & 55.0752 & 25 May (09:47) & 7.3080 & 55.1360 & 87.4 & 12.2 & 3.7 \\
\hline 3 & MD03i & 21 May (17:13) & 7.1480 & 55.0750 & 25 May (09:59) & 7.2526 & 55.1160 & 85.7 & 8.1 & 3.7 \\
\hline 4 & MD03i & 21 May (17:36) & 7.1426 & 55.0786 & 24 May (15:00) & 7.2960 & 55.0626 & 66.6 & 10.0 & 2.9 \\
\hline 5 & MD03i & 27 May (09:49) & 5.9126 & 54.3752 & $15 \mathrm{Jul}(01: 28)$ & 8.4680 & 55.1232 & 1264.0 & 184.4 & 48.7 \\
\hline 6 & MD03i & 27 May (16:01) & 6.0446 & 54.2024 & $20 \mathrm{Jul}(23: 15)$ & 8.0944 & 55.1930 & 1467.7 & 172.1 & 54.3 \\
\hline 7 & ODi & 30 May (08:36) & 6.7516 & 54.6712 & 8 Jun (09:59) & 8.2360 & 55.7702 & 273.2 & 154.6 & 9.1 \\
\hline 8 & ODi & 30 May (12:09) & 6.7476 & 54.2554 & 9 Jul (19:15) & 8.5282 & 55.2812 & 1203.0 & 161.8 & 40.3 \\
\hline 9 & ODi & 31 May (07:46) & 7.8816 & 54.0842 & 24 Jun $(03: 28)$ & 8.8360 & 54.1316 & 844.3 & 62.6 & 23.8 \\
\hline
\end{tabular}

Type: two drifter types used (see Fig. 1). Length: sum of the lengths of linear segments connecting observed drifter locations. Dist: linear distance between the first and last drifter locations observed. $\Delta T$ : days between the first and the last observation. Drifter nos. 2, 3 and 4 travelling for only few days were ignored for this study.

The paper is organized as follows: Sect. 2 documents how observations were taken (Sect. 2.1) and how corresponding model simulations were performed (Sect. 2.2). Section 2.3 describes two data sets used for characterizing residual current variability in the German Bight on a daily basis. Results (Sect. 3) are presented in two parts: Sect. 3.1 provides a synoptic description of all drifters deployed and places observations into the context of ambient atmospheric and marine conditions; Sect. 3.2 provides the analysis of how corresponding model simulations match observations. First, full simulated trajectories are presented using currents from TRIM or BSHcmod, the latter also combined with wind drag and Stokes drift, respectively. A more detailed evaluation of model performance is then based on subdividing drift trajectories into segments of $25 \mathrm{~h}$ length. Results are discussed in Sect. 4; main conclusions are provided in Sect. 5.

\section{Material and methods}

\subsection{Drifter observations}

In May 2015, a total of nine drifters were deployed at different locations in the German Bight (North Sea) during the FS Heincke cruise HE 445. The raw data are freely accessible at Carrasco and Horstmann (2017). Table 1 specifies each drifter's launch position and launch time as well as its last position, the total length of its trajectory and the simple linear distance between its initial and final locations. Drifter nos. 2, 3 and 4, travelling for only few days, were ignored for this study. All drifters obtained their positions via the Global Positioning System (GPS) and communicated them to the lab via the satellite communication network Iridium. Three drifters could successfully be tracked for between 40 and 54 days. In order to conserve battery power, an initial sampling rate of about once every $15 \mathrm{~min}$ was later reduced to once every $30 \mathrm{~min}$.
Two different drifter types were utilized (see Table 1). The first drifter type, MD03i, from Albatros Marine Technologies (Fig. 1a) is cylinder shaped with a diameter of $0.1 \mathrm{~m}$ and a length of $0.32 \mathrm{~m}$. Only $\sim 0.08 \mathrm{~m}$ of the drifter protrude from the water surface when deployed (Fig. 1b). The second drifter type, ODi from the same manufacturer (Fig. 1c), has a spherical shape with $0.2 \mathrm{~m}$ diameter, with about half of it protruding from the water surface. The ratio of drag area in the water to drag area outside the water was 33.2 for the MD03i and 16.9 for the ODi model, respectively. To both drifters, a drogue with $0.5 \mathrm{~m}$ length and diameter (e.g. Fig. 1a) was attached $0.5 \mathrm{~m}$ below the sea surface. Due to this drogue and the small sail area exposed to winds above the water surface, drifter movements are supposed to be representative of currents in a surface layer of about $1 \mathrm{~m}$ depth. It must be noted, however, that drifters deployed had no drogue presence sensors.

\subsection{Drifter simulations with PELETS-2D}

For drifter simulations, we used the Lagrangian transport module PELETS-2D (Program for the Evaluation of Lagrangian Ensemble Transport Simulations; Callies et al., 2011) developed at Helmholtz-Zentrum Geesthacht (HZG). The PELETS algorithm was designed for particle tracking on two-dimensional unstructured triangular grids. As both models underlying this study use regular grids, the grid topology was preprocessed, splitting each rectangular grid cell into two triangles. Neither the number of nodes nor the information content of underlying hydrodynamic fields is affected by this formal procedure. The integration algorithm used is a simple Euler forward method. Particle velocities are updated (linear interpolation between two neighbouring nodes) each time a particle leaves a cell of the triangular grid. If no edge is reached within the maximum time step of $15 \mathrm{~min}$, velocities are updated based on linear interpolation between three nodes. 


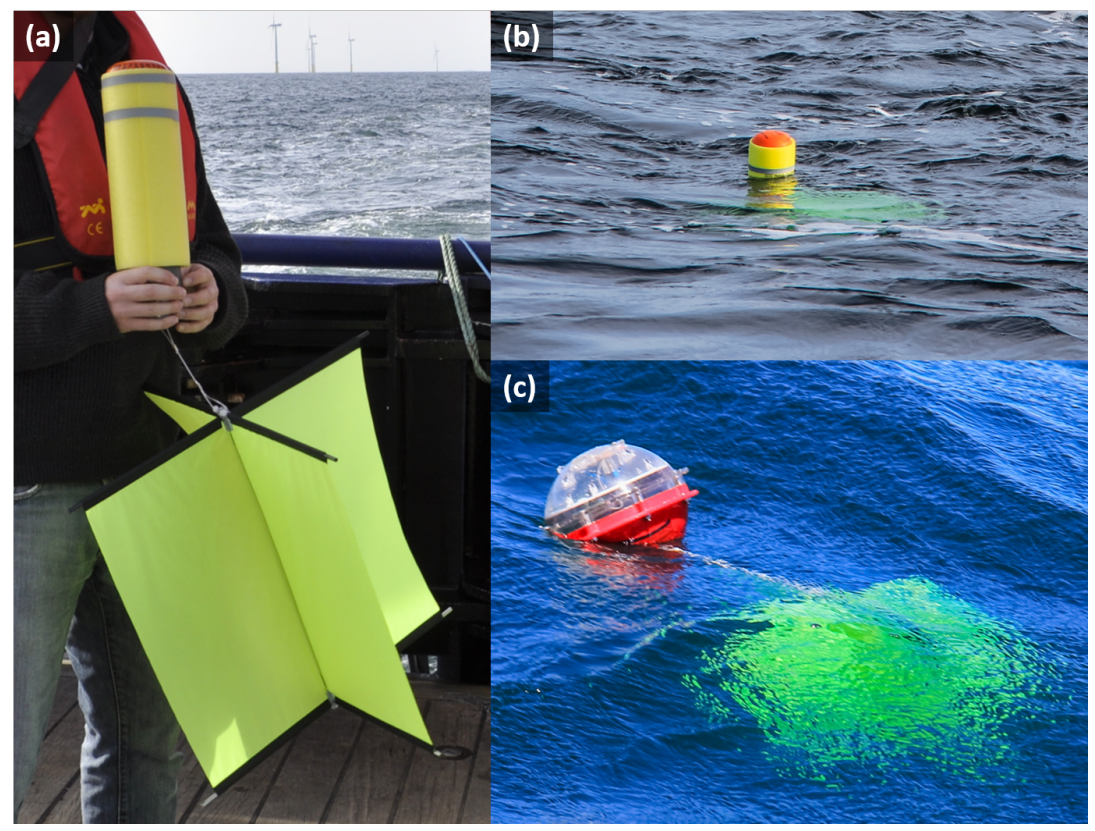

Figure 1. Drifter types MD03i (panels a and b) and ODi (panel c) used during the experiment. Both drifter types were photographed shortly after launch so that the drogues had not yet settled.

The following equation is used for simulating drifter location $\boldsymbol{x}$ as function of time $t$ :

$$
\frac{\mathrm{d} \boldsymbol{x}}{\mathrm{d} t}=\boldsymbol{u}_{\mathrm{E}}+\alpha \boldsymbol{u}_{\mathrm{S}}+\beta \boldsymbol{u}_{10 \mathrm{~m}}
$$

Here, $\boldsymbol{u}_{\mathrm{E}}$ denotes Eulerian marine surface currents calculated with either BSHcmod (Sect. 2.2.1) or TRIM (Sect. 2.2.2), $\boldsymbol{u}_{\mathrm{S}}$ is the surface Stokes drift obtained from wave model WAM and $\boldsymbol{u}_{10 \mathrm{~m}}$ is the $10 \mathrm{~m}$ height wind vector. Coefficients $\alpha$ and $\beta$ are weighting factors (see Sect. 2.2.3). Equation (1) describes windage (or leeway) as a drag in downwind direction, neglecting any cross-wind lift component. Such lift component depending on the specific overwater structure of a drifting object is crucial for search and rescue (Breivik and Allen, 2008). For surface drifters used in experiments, however, these effects should be negligible.

Throughout this study, Stokes drift and wind drag will not be considered in combination but rather as alternative options. Therefore, at least one of the two weighting factors $(\alpha$ or $\beta$ ) in Eq. (1) will always be set to zero. Drift paths were calculated offline based on archived data. Sub-grid-scale turbulence effects implemented in PELETS-2D in terms of random movements were deactivated.

\subsubsection{BSHcmod}

BSHcmod is run operationally by the Federal Maritime and Hydrographic Agency (BSH) on a two-way nested grid for the North Sea and Baltic Sea. A description of the 3-D model can be found in Dick et al. (2001). Horizontal resolution in the German Bight is about $900 \mathrm{~m}$; the vertical coordinate is dynamical (Dick et al., 2008). Atmospheric forcing of BSHcmod is taken from the regional model COSMO-EU (Consortium for Small-Scale Modelling; Schulz and Schättler, 2014). This operational atmospheric model of the German Meteorological Service (Deutscher Wetterdienst - DWD) has a spatial resolution of $7 \mathrm{~km}$; output is stored on a hourly basis. For BSHcmod, winds are interpolated to a $15 \mathrm{~min}$ model time step. The parametrization by Smith and Banke (1975) is used to include wind stress. The option to include Stokes drift from surface wave models (as described in Dick et al., 2001) is not activated operationally so that effects of Stokes drift are also not included in archived model output.

Archived surface current data represent approximately the upper $5 \mathrm{~m}$ of the water column. Higher-resolution output of the operational model BSHcmod (version 4) was regridded accordingly, conserving transport rates. Time resolution of archived data is $15 \mathrm{~min}$. Although operationally BSHcmod is run in combination with its own Lagrangian transport module (Maßmann et al., 2014); for the present study, this module was replaced by PELETS-2D, which provides convenient interfaces to both BSHcmod and TRIM.

\subsubsection{TRIM}

TRIM solves the hydrodynamic equations on a Cartesian grid, allowing for coastal regions that are falling dry. Casulli and Stelling (1998) provide a description of the numerical implementation; extensions with regard to parallelization and nesting can be found in Kapitza (2008). After three refinements nested one way into a coarse grid with $12.8 \mathrm{~km}$ resolution covering the north-eastern Atlantic, North Sea and 

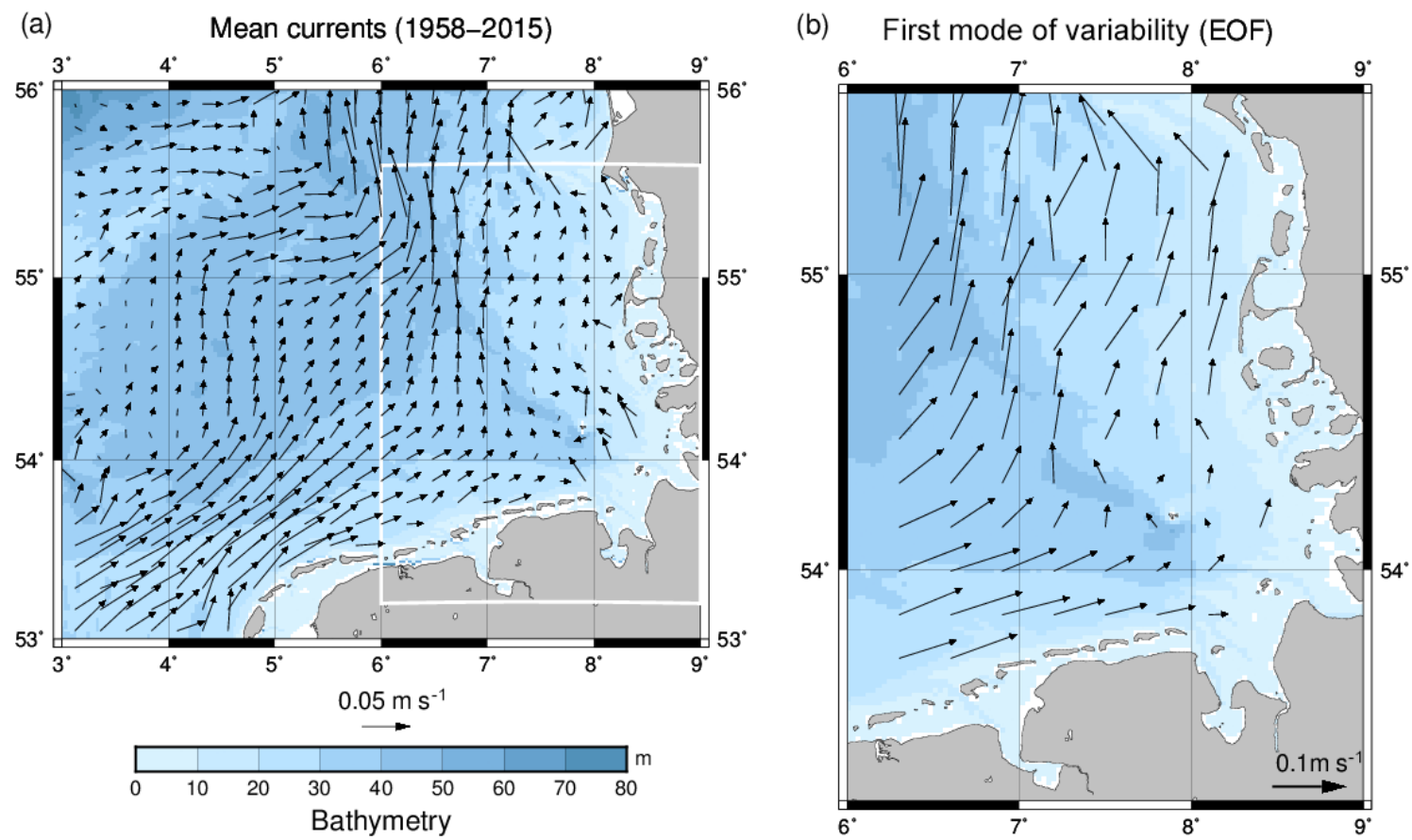

Figure 2. (a) Mean currents in the inner German Bight, calculated running a 2-D version of model TRIM for the period January 2014August 2015. (b) Leading mode of variability (first empirical orthogonal function (EOF); see von Storch and Zwiers, 1999) of daily $25 \mathrm{~h}$ mean currents obtained from a PCA restricted to data from the white box region in panel (a) (Callies et al., 2017). Vector densities in the two plots do not represent spatial resolution of the underlying model $(1.6 \mathrm{~km})$. Vectors in the right panel are scaled in such a way that the EOF represents an anomaly that would arise from the first principal component $\left(\mathrm{PC}_{1}\right)$ assuming the (positive) value of 1 standard deviation.

Baltic Sea, resolution in the German Bight is $1.6 \mathrm{~km}$. The FES2004 tidal model (Lyard et al., 2006) is used to determine tidal signals at the lateral boundaries of the outer coarse grid. Hourly values of wind and sea level pressure are taken from COSMO-CLM hindcasts (Geyer, 2014), which resulted from a regionalization of global NCEP/NCAR Reanalysis-1 data (Kistler et al., 2001) using a spectral nudging technique (von Storch et al., 2000). Similar to BSHcmod, wind stress was parametrized according to Smith and Banke (1975), a parametrization validated from gentle breeze to gale force winds. An evaluation of TRIM simulations on a $6.4 \mathrm{~km}$ grid (first of three refinements applied in the present study) can be found in a recent model intercomparison study regarding simulations for the whole North Sea (Pätsch et al., 2017).

\subsubsection{Effects of winds and waves}

Simulated Eulerian currents can usually not fully reproduce observed currents. Additional wind effects may manifest themselves in different ways. This study explores the strengths of windage effects and Stokes drift as alternative tuning parameters for optimizing simulated drift trajectories.

Hourly fields of surface Stokes drift were simulated with the third-generation spectral wave model WAM (WAMDIGroup, 1988; Komen et al., 1996), extending an existing wind-wave hindcast for the years 1949-2014 (Groll and
Weisse, 2017) and including surface Stokes drift as a new element of archived model output. Wave simulations were driven with the same COSMO-CLM hindcast also used for TRIM simulations. The wave model was used in a nested mode, with the finer spatial resolution of about $3 \times 3$ nautical miles over the entire North Sea. Wave breaking and depth refraction were enabled. A more detailed description of the wave simulation and its validation is given by Groll and Weisse (2017). For the present study, no assumption about the vertical profile of Stokes drift (Breivik et al., 2016, for instance) was made. Instead, the empirical weighting factor $\alpha$ in Eq. (1) was used to translate surface Stokes drift obtained from WAM into a value relevant for drifters that represent displacements in a surface layer of approximately $1 \mathrm{~m}$ depth. Choosing $\alpha=0.5$ resulted in a reasonable overall fit with observations (see below).

Windage (or leeway) effects occur when drag resulting from part of a drifter being exposed to the wind is not fully compensated by a drogue attached to the drifter. Generally, the direct influence of winds on the drifter type used in this experiment is supposed to be small as long as the drogues attached are in a proper condition. However, specification of windage effects may also be needed when model currents used do not adequately represent the surface layer drifters are immersed in. An extra wind drift parametrized as $0.6 \%$ of $10 \mathrm{~m}$ wind velocity was used in combination with archived 
BSHcmod currents averaged over a $5 \mathrm{~m}$ depth surface layer. By contrast, drift simulations based on TRIM output ( $1 \mathrm{~m}$ deep top layer) were performed without taking into account additional wind effects.

The assumed strengths of either wind forcing or Stokes drift resulted from trying to achieve an overall eastward displacement of simulated drifters that roughly agreed with observations. This approach must not be confused with sound model calibration, which seems impossible based on the very limited data available. Models perform differently during different periods, and it is hard to distinguish, for instance, between deficiencies in the hydrodynamic model and implications of imperfect atmospheric forcing. Also, independent data needed for model validation are not available. However, already the simple approach enables an appraisal of how drifter simulations will depend on a distinction between wind drag and Stokes drift.

\subsubsection{Analysis of $25 \mathrm{~h}$ drifter displacements}

Comparing simulated trajectories with concurrent observations enables a qualitative assessment of a model's ability to reproduce overall drift patterns. However, accumulation of possibly intermittent simulation errors makes it difficult to localize the origin of major deviations in either space or time. Therefore, a series of short-term $(25 \mathrm{~h})$ simulations was started once per day (13:00 UTC) from each drifter's observed location at that time. The short-term simulation errors were analysed against the backdrop of prevailing winds and residual currents (see Sect. 2.3).

\subsection{Characterization of residual currents on a daily basis}

BSH classifies the residual circulation in the German Bight (between 53.25 and $55.5^{\circ} \mathrm{N}$ and between 6.5 and $9.0^{\circ} \mathrm{E}$ ) on a daily basis, referring to surface currents from BSHcmod. The classification ${ }^{1}$ is performed manually based on subjective assessments of $24 \mathrm{~h}$ averages. The small deviation of the averaging interval from two tidal periods does not affect the analysed frequency distribution of circulation patterns. Most frequent are a cyclonic circulation with a pronounced inflow at the south-western border and outflow at the northern border, a reverse anticyclonic circulation and a category with variable current patterns. Cyclonic circulations correspond with what is observed in the long-term mean (see Fig. 2a). Six specific directional types with currents towards the east, west, north, south, north-west and south-east play only minor roles. They are related to strong local winds and for statistical purposes combined into just one class. Due to topographical constraints, south-west and north-east patterns do not occur. Figure 3 includes results of the BSH classifications for the period relevant in this study.

\footnotetext{
${ }^{1}$ http://www.bsh.de/de/Meeresdaten/Beobachtungen/ Zirkulationskalender_Deutsche_Bucht/index.js
}

An alternative analysis is based on the 2-D version of TRIM. Slightly different from the above approach, Callies et al. (2017) defined residual currents as $25 \mathrm{~h}$ means (close to one lunar day $-24.8 \mathrm{~h}$ ). A principal component analysis (PCA) was performed on these residual currents, focusing on the inner German Bight (east of $6.0^{\circ} \mathrm{E}$ and south of $55.6^{\circ} \mathrm{N}$; see Fig. 2b) and excluding inshore areas with a bathymetric depth of below $10 \mathrm{~m}$. Corresponding data are freely accessible at Callies (2016). Figure $2 \mathrm{~b}$ displays the leading mode of variability (first empirical orthogonal function (EOF); see von Storch and Zwiers, 1999). The time series of corresponding principal component $\mathrm{PC}_{1}$ is shown in Fig. 3. The structure of the dominant residual current anomaly pattern (explaining more than $70 \%$ of variability) roughly agrees with that of long-term mean residual currents in the area of the white box in Fig. 2a.

\section{Results}

\subsection{Observations}

Figure 3 places drifter schedules into the context of variable atmospheric winds and marine residual currents. Time bars show travel times of all nine surface drifters. To facilitate a synopsis of synchronous drifter movements, the time coordinate was segmented, subjectively assigning different colours to periods with different drift behaviour. In this context, a continuous daily index was introduced, counting days since when the first $25 \mathrm{~h}$ simulation for drifter no. 5 was started on 27 May at 13:00 UTC (see Table S1). To represent atmospheric forcing used in BSHcmod and TRIM, respectively, simulated $10 \mathrm{~m}$ winds at $55^{\circ} \mathrm{N}$ and $7^{\circ} \mathrm{E}$ near the centre of the study area are shown together with observations on the island of Heligoland $\left(54.10^{\circ} \mathrm{N}, 7.53^{\circ} \mathrm{E}\right)$. All wind vectors represent $25 \mathrm{~h}$ means and are plotted at the centre of the respective $25 \mathrm{~h}$ interval starting at 13:00 UTC. The winds from three different data sources are in reasonable agreement with each other.

Figure 3 also includes the representation of (a) the subjective classification of daily mean BSHcmod surface currents and (b) the first principal component $\left(\mathrm{PC}_{1}\right)$ of $25 \mathrm{~h}$ mean currents simulated with a 2-D version of TRIM (see Sect. 2.3). Positive values of $\mathrm{PC}_{1}$ (i.e. amplitudes of the anomaly pattern shown in Fig. 2b) indicate a strengthening of the mean cyclonic circulation; negative values refer to its weakening or even reversal. Although the two representations of residual current variability have different roots (different models, surface layer vs. vertical means, subjective vs. objective, different atmospheric forcing), a clear correspondence between the two representations is discernible. Cyclonic hydrodynamic regimes and positive values of $\mathrm{PC}_{1}$ tend to coincide with winds from the south-west, while anticyclonic circulations and negative $\mathrm{PC}_{1}$ values are mainly driven by winds from the north-west (Callies et al., 2017). 
Schedule of drifter tracks and residual current variability

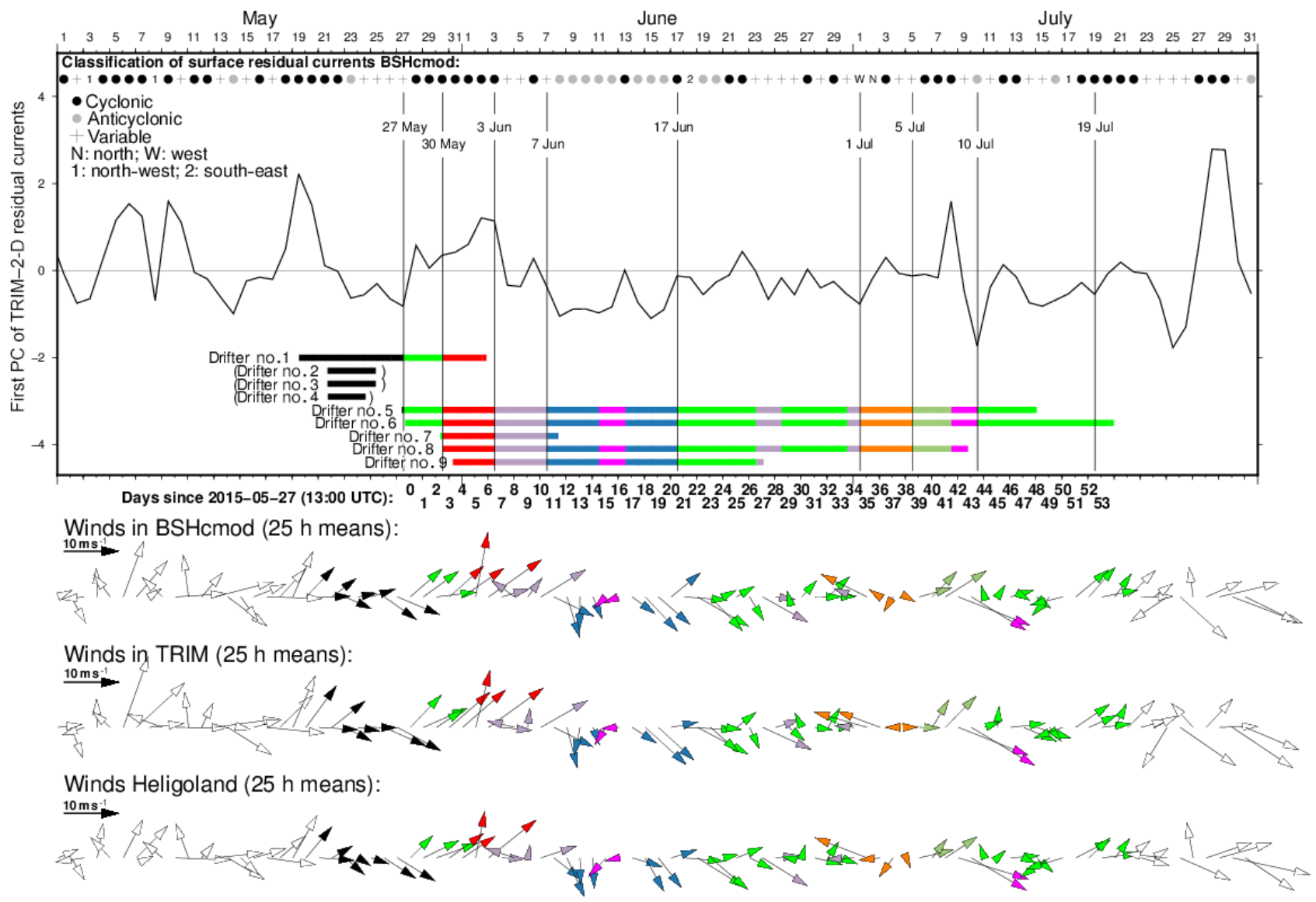

Figure 3. Time bars indicate for each drifter the period for which corresponding simulations were performed (drifter nos. 2,3 and 4 were disregarded in this study). A colour code defined in Table S1 (the Supplement) was used for time segmentation. Symbols at the top represent the classification of daily surface residual currents based on BSHcmod. In addition, the time series of the leading principal component ( $\left.\mathrm{PC}_{1}\right)$ of $25 \mathrm{~h}$ mean currents simulated with TRIM-2D is shown (see Sect. 2.3). PC $_{1}$ values were normalized with their standard deviation during the years 1958-2015. Positive $\mathrm{PC}_{1}$ values represent a strengthening of the cyclonic regime; negative values represent its weakening or even reversal (see Fig. 2). The $25 \mathrm{~h}$ mean wind vectors ( $10 \mathrm{~m}$ height) used in the two model systems (both extracted for the location at $55^{\circ} \mathrm{N}$ and $\left.7^{\circ} \mathrm{E}\right)$ are contrasted with observations on the island of Heligoland $\left(54.10^{\circ} \mathrm{N}, 7.53^{\circ} \mathrm{E}\right)$.

Figure 4 shows six observed drifter trajectories, disregarding the tracks of drifter nos. 2, 3 and 4 that were recorded for just a few days. A feature shared by at least four drifters (nos. $5,6,7$ and 8) is a general displacement towards the northeast. Concerning drifter nos. 6 and 8, an interesting special situation occurs during 7-16 June (days 11-20). Figure 5 shows the distance between the two drifters as a function of time. At the deployment of drifter no. 8 (30 May, day 3), drifter no. 6 had already travelled for nearly 3 days and was located at a distance of about $20 \mathrm{~km}$ from drifter no. 8. During the next 4 days, the two drifters further separated. On 4 June (day 8), however, they suddenly started converging quickly. From 8 June (day 12) onward, drifter nos. 6 and 8 stayed at a distance of less than $2 \mathrm{~km}$ for nearly 10 days. Just after the distance had reached its minimum (about $800 \mathrm{~m}$ ), the drifters started to separate again. Other short periods of fast convergence occurred later but never again did the two drifters come that close. During the last 8 days of their joint journey (starting at around day 35), the distance between the two drifters showed particularly large oscillations (Fig. 5).

Figure 6 provides magnitudes of velocities for drifter nos. $5,6,8$ and 9 , calculated from velocity vectors smoothed using a $25 \mathrm{~h}$ moving average of hourly data. Drifter movements are particularly fast in the beginning (days 5-6), brought about by persistent south-westerly winds and a corresponding cyclonic circulation at that time (Fig. 3). Other periods with particularly fast movements occur around day 35 and days 42-43. In the former case, strong winds from the southeast trigger a very fast separation of drifter nos. 6 and 8 (see Fig. 5). In the latter case, north-westerly winds give rise to extreme drift speeds in the south-east direction. Drifter nos. 5 and 8 are already in near-shore areas at that time (Fig. 4).

In their central parts, drifter trajectory nos. 5, 6 and 8 exhibit variable drift directions but mostly moderate drift ve- 

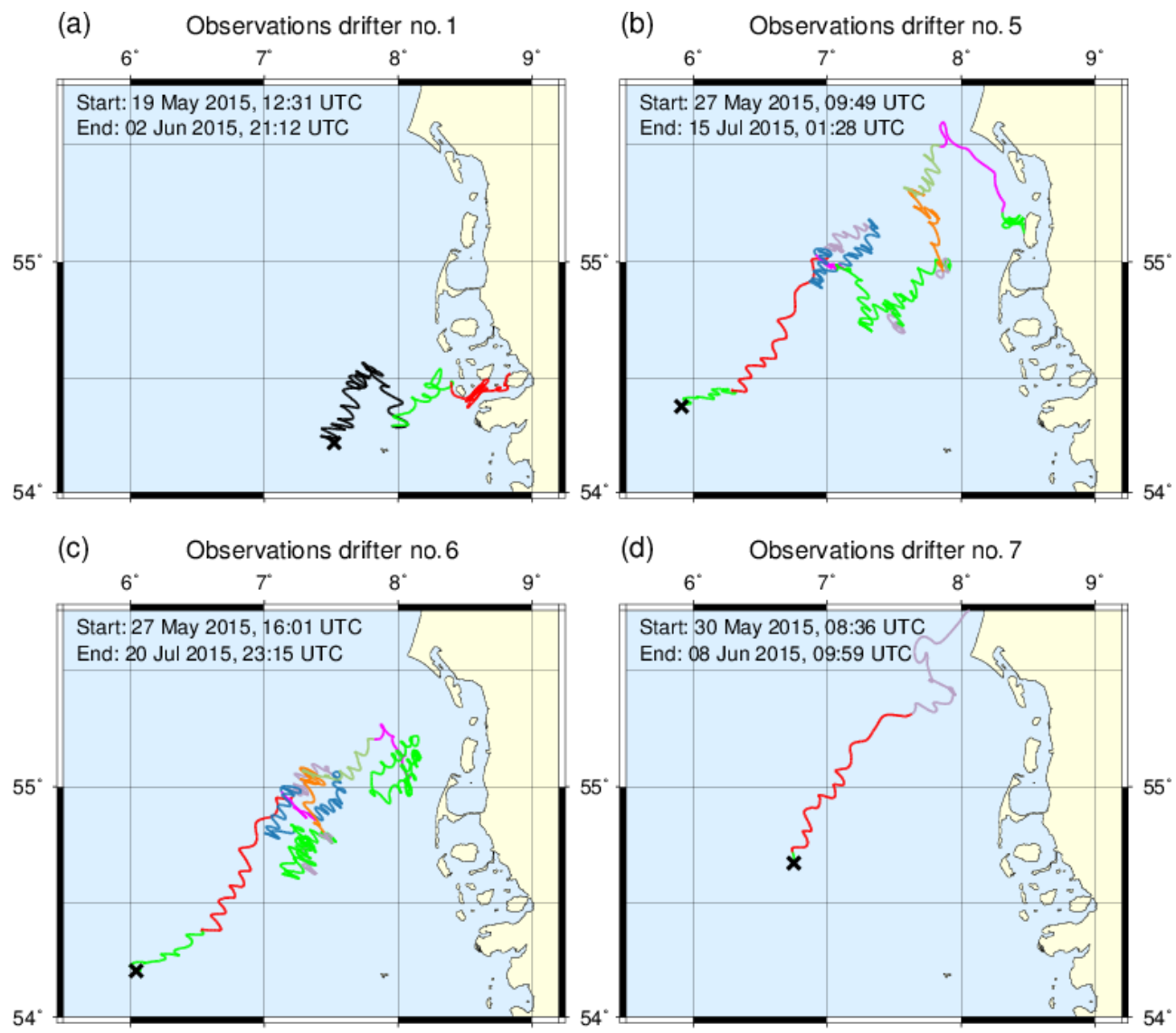

(d)

(d) Observations drifter no. 7

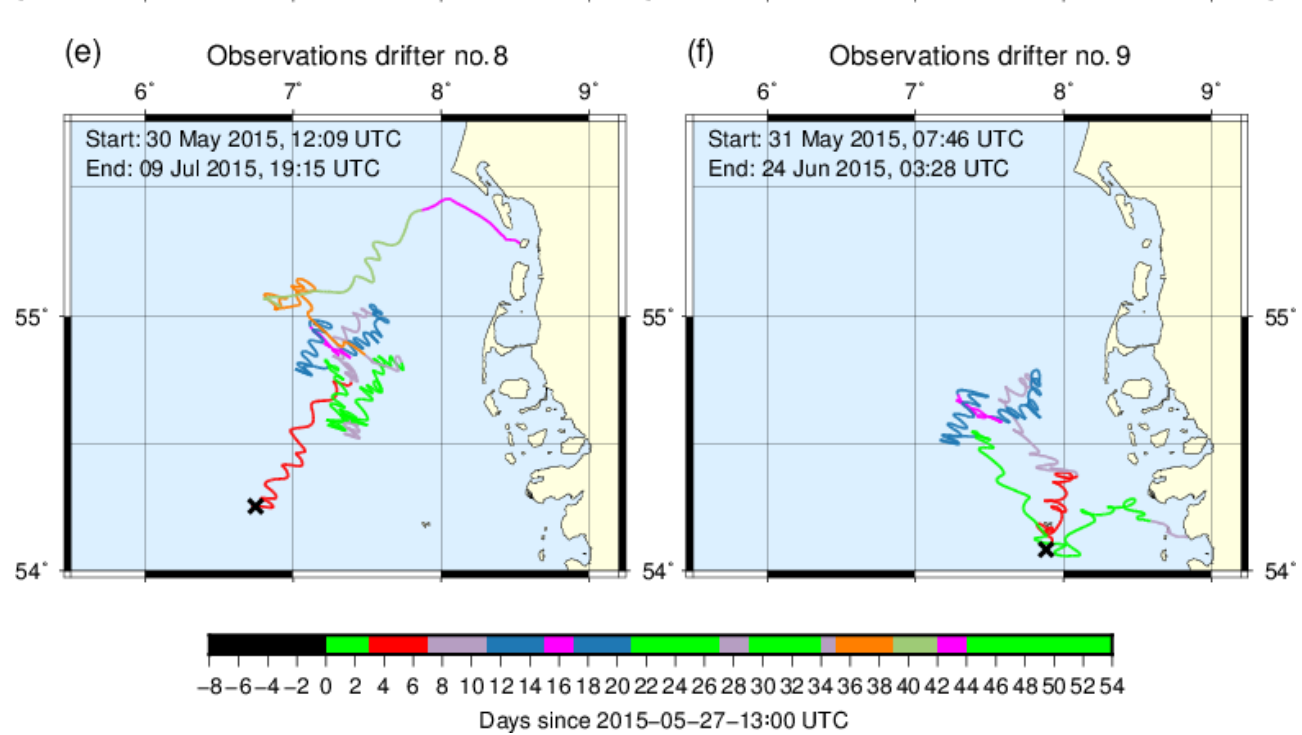

Figure 4. Observed trajectories of six drifters deployed at the locations indicated by black crosses. Drift paths were segmented using the colour code introduced in Table S1. The numerical data underlying this plot can be found in the Supplement.

locities (Fig. 6). Although trajectories are complex (Fig. 4), they show resemblance, explicable by moderate distances between the three drifters. In the beginning of its journey, drifter no. 9, having started further away in the south-east of the domain, behaves differently (days 4-9; see Fig. 6).
A much better coherence with other drift paths is found during days 11-20 (7-16 June) characterized by the close proximity of drifter nos. 6 and 8. The journey of drifter no. 1 has just a small overlap with those of other drifters; the drifter is soon trapped within the entrance to tidal basins (Fig. 4a). 
Observed distances between drifter nos. 6 and 8

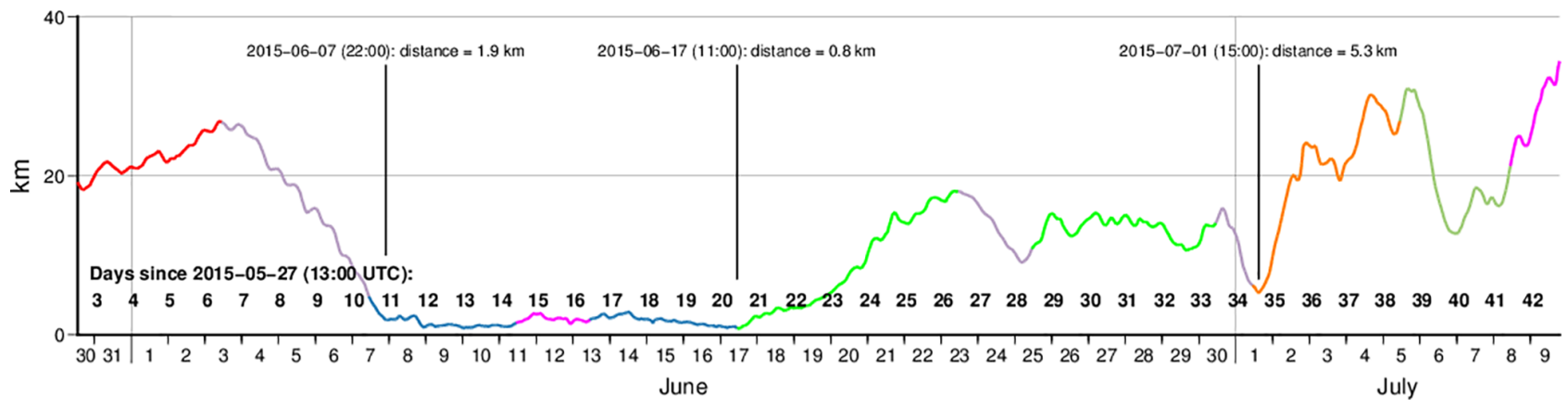

Figure 5. Observed distances between drifter nos. 6 and 8. Colours refer to those specified in Table S1.

Magnitudes of drift velocities (25 $\mathrm{h}$ moving averages)

Observations: coloured $\quad$ BSHcmod+W: $-\quad$ Windage in BSHcmod+W: $---\quad$ Stokes drift in BSHcmod+S: $\cdots \cdots$
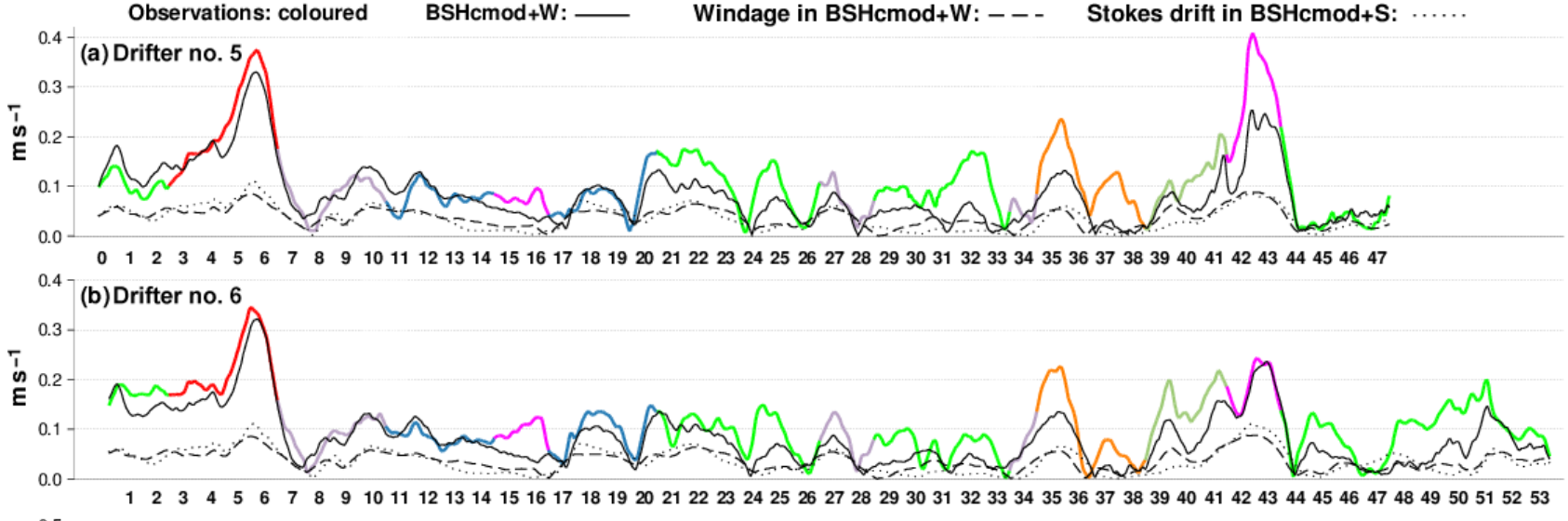

0.5 (c) Drifter no. 8
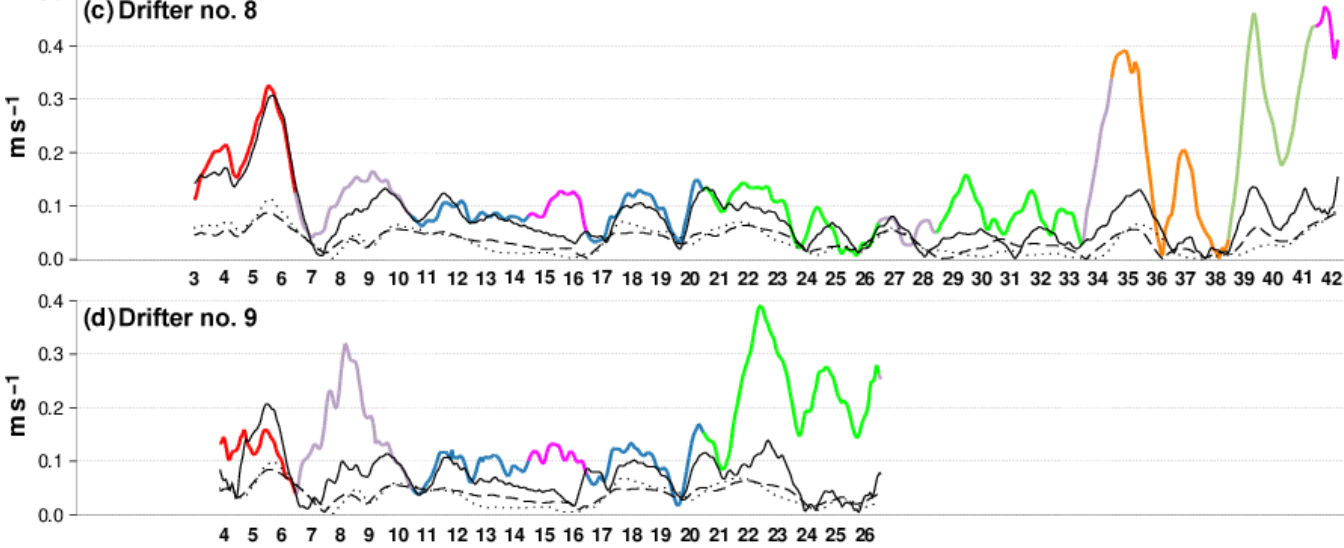

Days since 2015-05-27 (13:00 UTC)

Figure 6. Magnitudes of $25 \mathrm{~h}$ moving averages of drift velocity vectors, considering drifter nos. 5, 6, 8 and 9. Magnitudes of observed velocity vectors (coloured) are compared with simulations based on BSHcmod $+\mathrm{W}$. In addition, magnitudes of windage (in BSHcmod $+\mathrm{W}$ ) and Stokes drift (in BSHcmod + S) are shown. All model values were interpolated to observed (not simulated) drifter locations prior to averaging.

Further details of observed trajectories will be addressed in Sect. 3.2 together with a presentation of corresponding simulations.

\subsection{Simulations}

Figures in the Appendix compare drift simulations based on TRIM (Fig. A4) with three different approaches based on BSHcmod. The three setups are (a) just Eulerian currents 
(BSHcmod; Fig. A1), (b) Eulerian currents plus windage (BSHcmod $+\mathrm{W}$; Fig. A2) or (c) Eulerian currents plus Stokes drift (BSHcmod + S; Fig. A3). Numerical data displayed in the graphs are provided in the Supplement. It appears that combining BSHcmod currents for a $5 \mathrm{~m}$ depth surface layer with either windage or Stokes drift brings corresponding simulations closer to both observations (Fig. 4) and simulations based on Eulerian surface currents from TRIM with $1 \mathrm{~m}$ vertical resolution (Fig. A4). A key effect of the inclusion of extra wind or wave effects is the intensification of westward transports in agreement with wind directions that occur most frequently. One should remember that achieving reasonable agreement between overall strengths of these transports in simulations and observations was the criterion which led to the specific values we assigned to $\alpha$ or $\beta$ in Eq. (1) (see Sect. 2.2.3).

Analysing short-term drifter displacements on a daily basis enables a more detailed assessment of model performance. Simulations of $25 \mathrm{~h}$ drift paths were initialized every day on days 0-53 at 13:00 UTC. Full sets of corresponding plots are provided in the Supplement. The first collection (SM1 in the Supplement) shows $25 \mathrm{~h}$ drifter displacements that were observed. The second (SM2 in the Supplement) compares corresponding simulations based on either BSHcmod or TRIM Eulerian currents with these observations. The third (SM3 in the Supplement) is similar except that BSHcmod currents are complemented by parametrized windage $(\mathrm{BSH}$ cmod $+\mathrm{W})$. Finally, the fourth collection (SM4 in the Supplement) compares BSHcmod simulations including either windage $(\mathrm{BSHcmod}+\mathrm{W})$ or Stokes drift (BSHc$\bmod +\mathrm{S})$.

Drawing on the material from SM3, Figs. 7-9 present results for 12 selected days, comparing simulations based on TRIM surface currents with those based on BSHcmod + W. Each panel combines all drifters that are available at the respective time. Observed drifter displacements are coloured in agreement with Table S1.

Concentrating on the four drifters that travelled longest, bars in Fig. 10a show daily values of separation between observed and simulated end points of $25 \mathrm{~h}$ drift paths, referring again to simulations with either TRIM or BSHcmod + W. To show the relative importance of drift errors, total distances covered according to observations or simulations are also included. Figure 10d shows the angles between observed and simulated drifter displacements. Time series ( $25 \mathrm{~h}$ means) of wind speeds used in TRIM and BSHcmod (and also BSHcmod + W) are shown in Fig. 10b together with surface Stokes drifts from wave model WAM. Figure 10c copies observed Heligoland wind vectors from Fig. 3.

The following description highlights some key aspects of drifter observations and concurrent simulations during different sub-periods of the experiment.

Days 0-6 (27 May-2 June): This is a period characterized by cyclonic residual currents increasing in strength
(Fig. 3). Driven by winds mainly from south-west, drifters move fast towards a north-eastern sector. Simulated drift distances agree well with observations. Appreciable errors for TRIM arise from moderate directional deviations in combination with large displacements (Fig. 7f).

On day 2, neither model simulates the neighbouring drifter nos. 5 and 6 to move into different directions (SM3). On day 3 (Fig. 7a and e), only BSHcmod $+\mathrm{W}$ captures the deviant direction of drifter no. 7. Comparing simulations based on BSHcmod + W (Fig. 7a) with those based on BSHcmod (SM2) reveals that the deviant simulation of drifter no. 7 arises from spatial variation of BSHcmod currents. By contrast, inclusion of more large-scale windage affects all drifters tracked in a very similar way. On day 6 (Fig. 7b and f), the again deviant movement of drifter no. 7 (now rotated to the opposite direction) is no longer reproduced by BSHcmod $+\mathrm{W}$.

For drifter no. 1, simulations are generally poor. On days $3-5$, the drifter already enters the complex coastal bathymetry which is insufficiently resolved in both models (e.g. Fig. 7a and e).

Days 7-10 (3-6 June): The strong cyclonic regime declines, strong south-west winds first cease and then blow from different directions (Fig. 3). Observed displacements of drifter nos. 5, 6 and 8 take a minimum on days 7 or 8 (Figs. 6 and 10a). On day 7, major directional errors occur under variable wind conditions (Figs. 7c, g and 10d). Only drifter no. 9 rotates its movement from north-east to north-west already on day 7; all other drifters follow on day 8 (Fig. 7d and h). Speed of drifter no. 9 shows a strong peak on day 8 (Fig. 6). Observed drifter displacements seem to decrease with distance from the coast, a variation not resolved in simulations (Fig. 7d and h). Also considering Stokes drift does not help reproduce this spatial gradient (SM4). Sub-mesoscale differences in drift speed (e.g. day 8; Fig. 7d) and direction (e.g. day 10; Fig. 8a) giving rise to the fast convergence of drifter nos. 6 and 8 (Fig. 5) remain unresolved in both models. Neither model captures the special behaviour of drifter no. 7 which continues its fast movement towards northern directions (compare Figs. A2d and A4d with Fig. 4d).

Days 11-14 (7-10 June): Winds from the north-west or north trigger an anticyclonic circulation (Fig. 3). On day 11 , the inclusion of windage greatly reduces errors of BSHcmod simulations for drifter nos. 6, 8 and 9 (compare Fig. 8b with SM2), mainly due to improved drift directions. Only for drifter no. 5, moving much slower despite its proximity to other drifters, adding windage leads to drift velocity on day 11 being greatly overestimated (Fig. 6). 

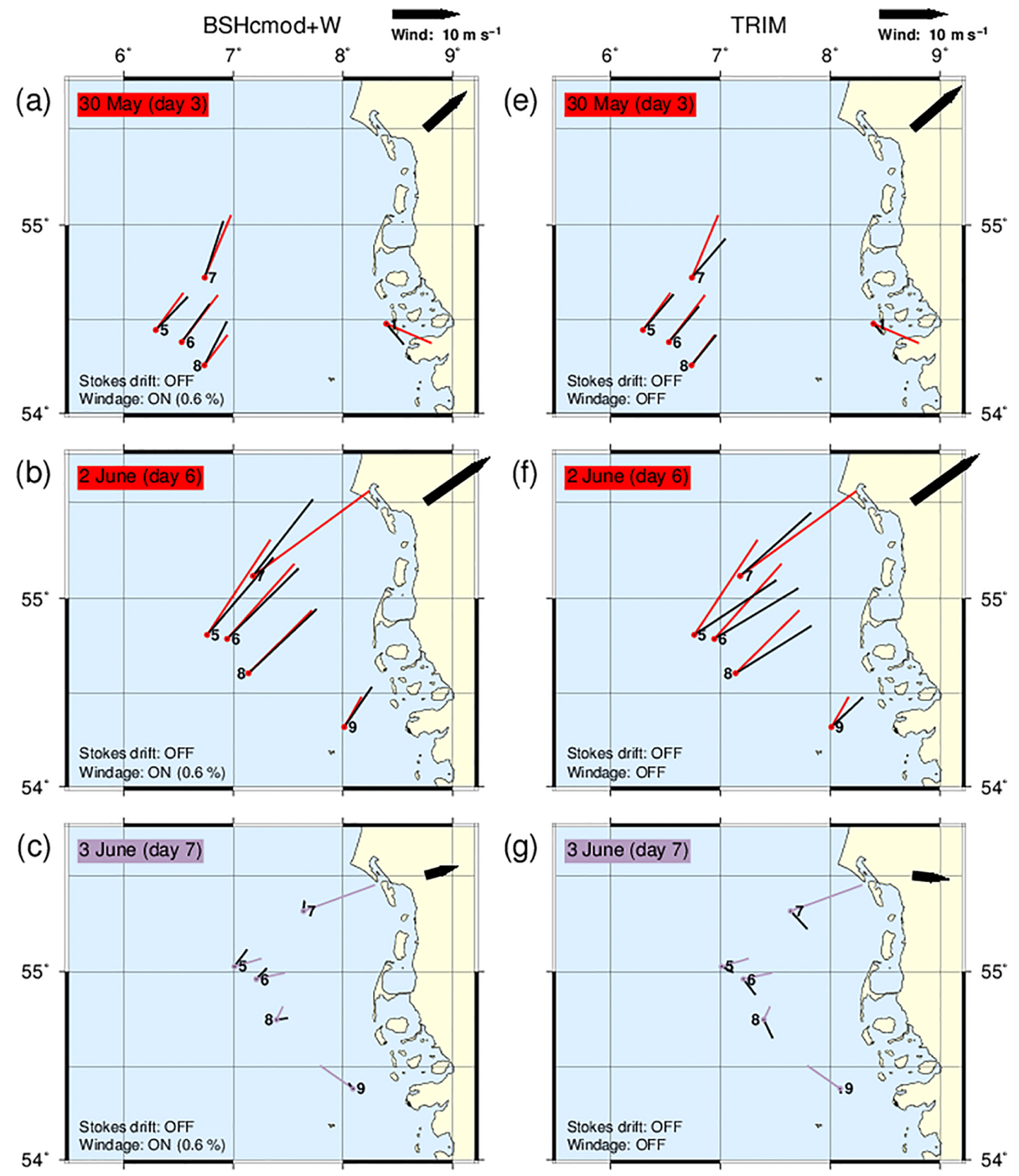

(g)
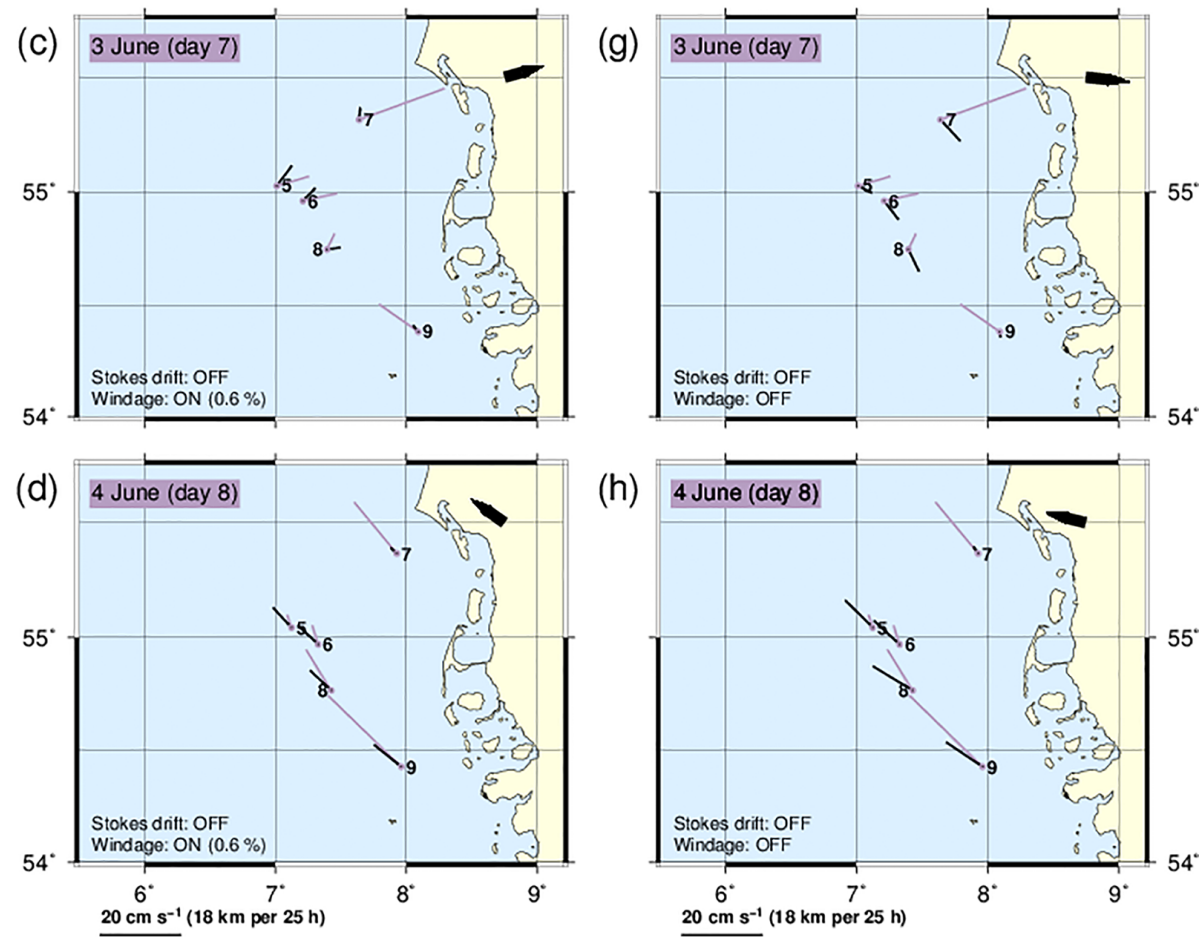

(h)

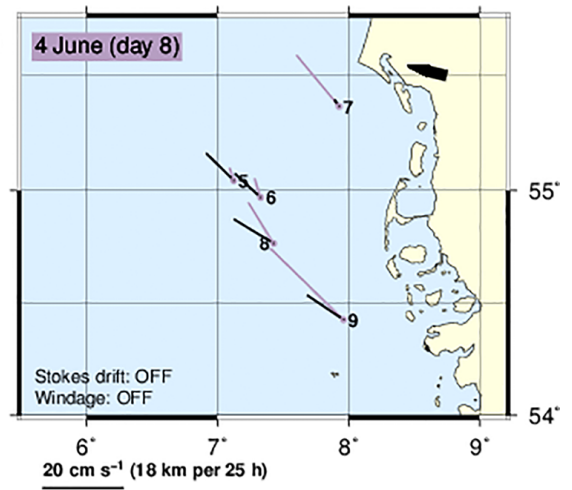

Figure 7. Observed $25 \mathrm{~h}$ drift paths (coloured in agreement with Table S1) are contrasted against concurrent simulations (black) based on BSHcmod + W (a-d) or TRIM (e-h). For 4 selected days, panels combine all drifters observed at the time of the plot. All drift distances were converted into $25 \mathrm{~h}$ mean drift velocities. Note that the length scales shown do not correspond with the spatial scale of the geographic map. Vectors in each panel's top right corner indicate the mean wind velocity vector at $55^{\circ} \mathrm{N}$ and $7^{\circ} \mathrm{E}$ derived from the respective atmospheric model used. 

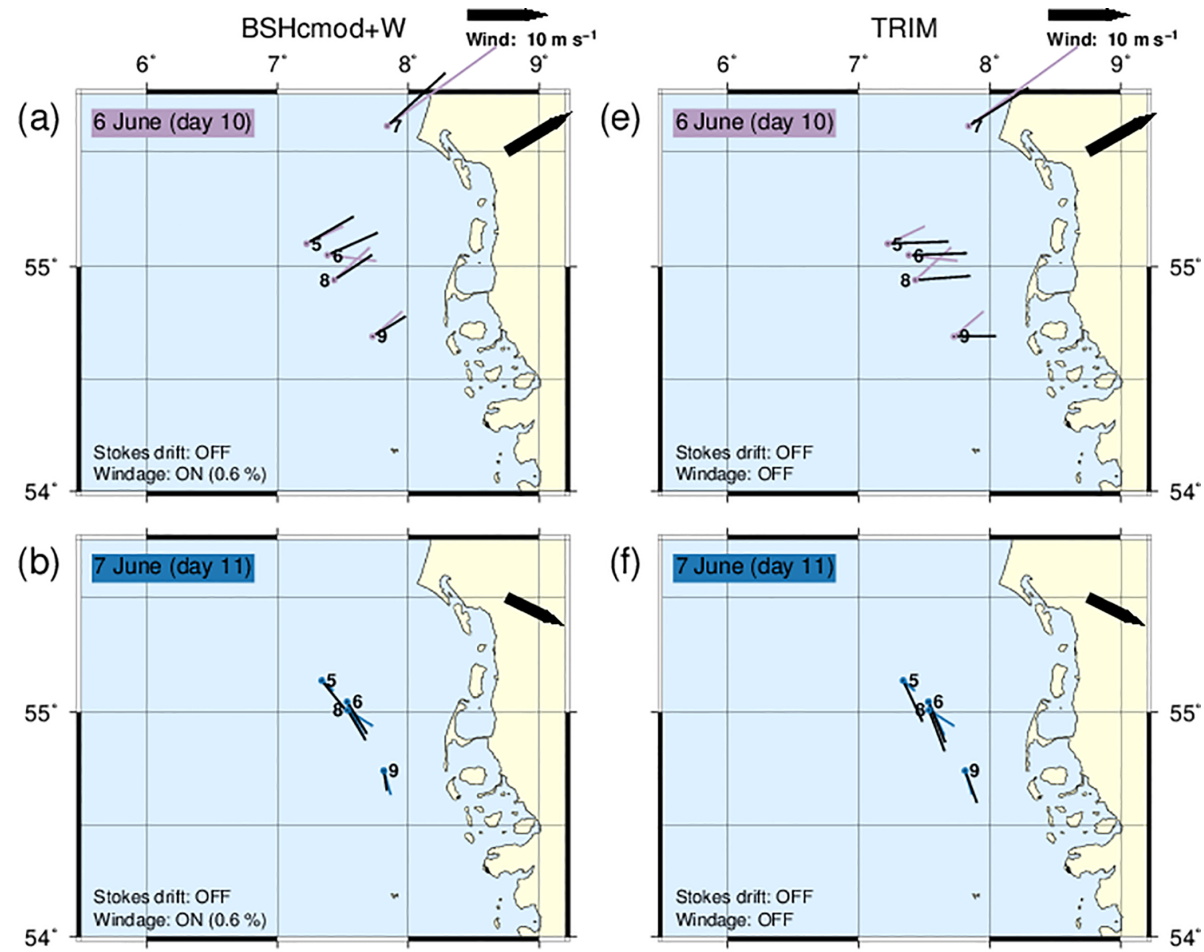

(f)
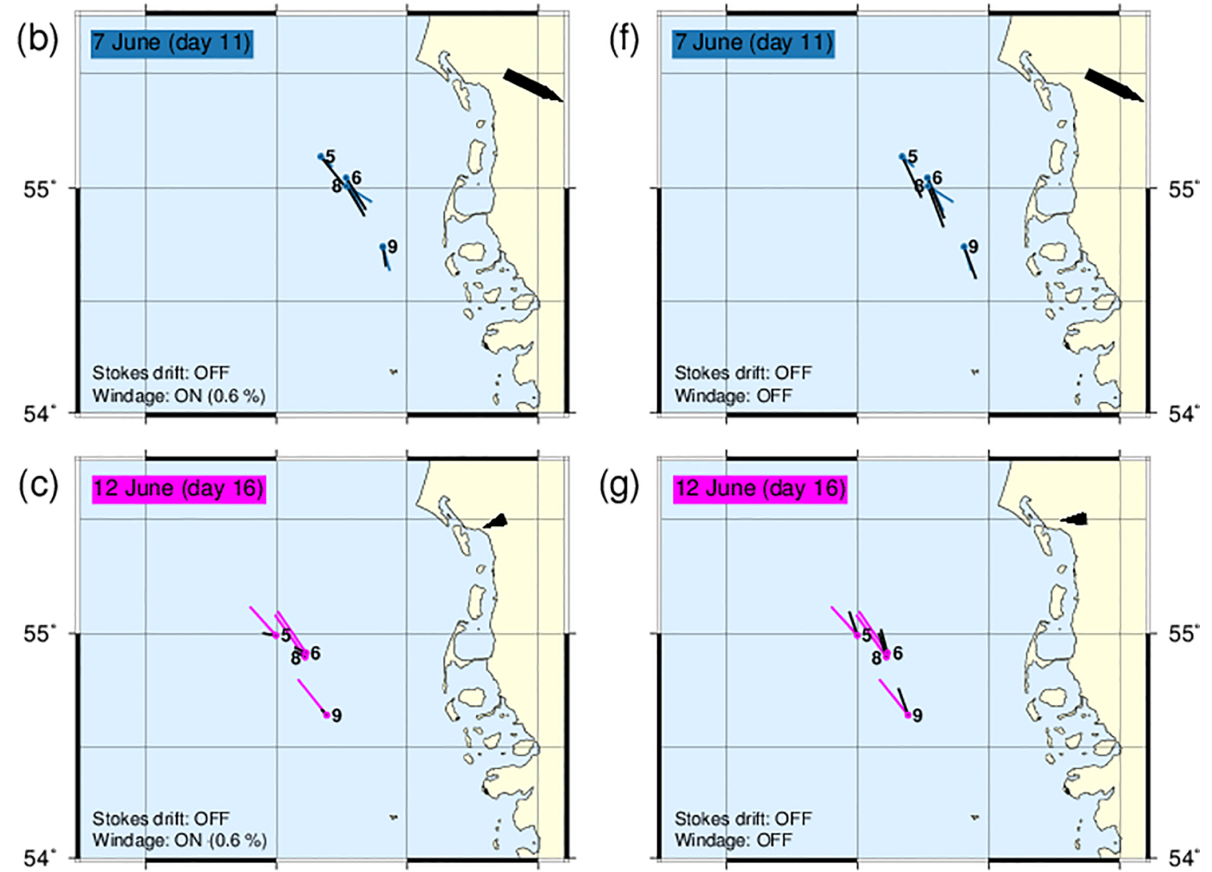

(g)
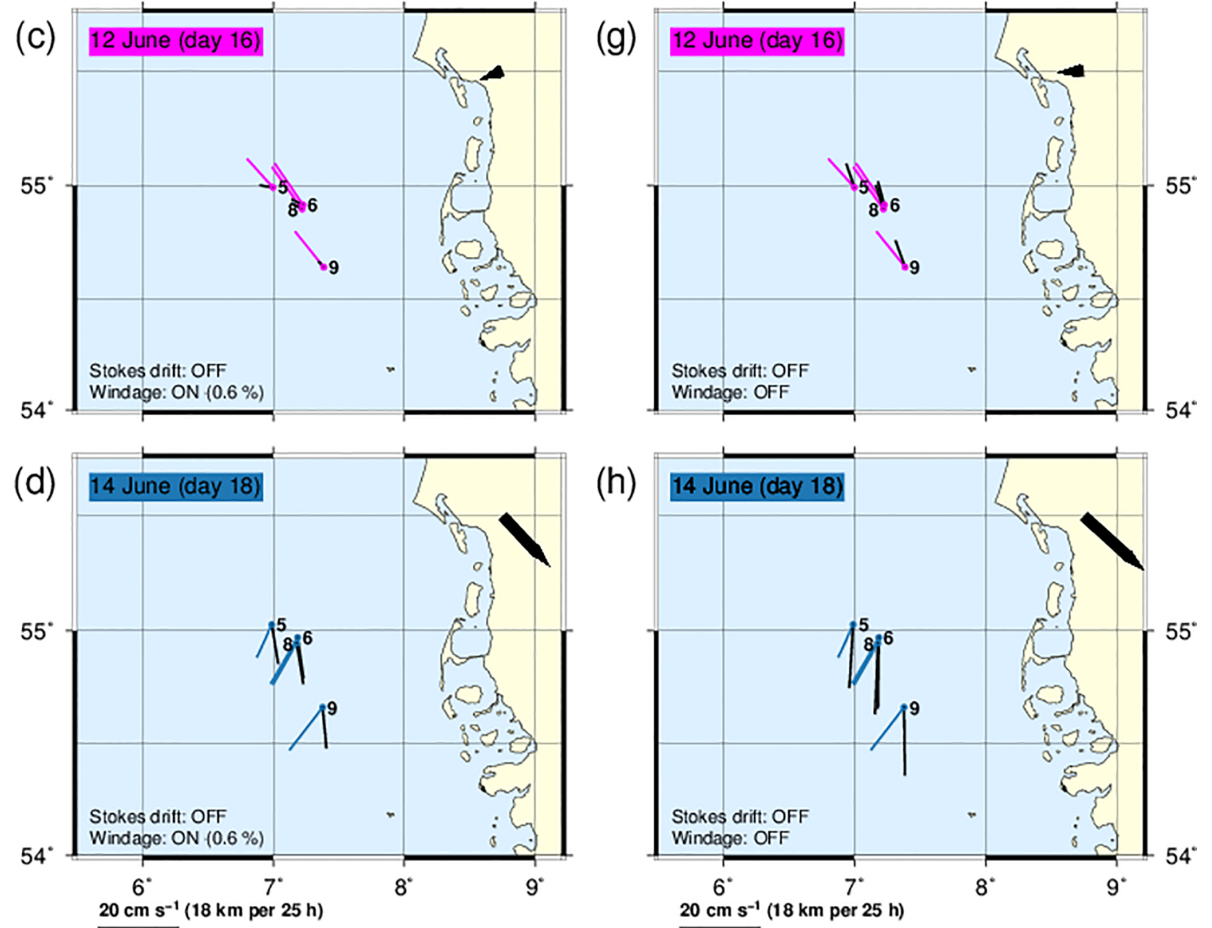

(h)

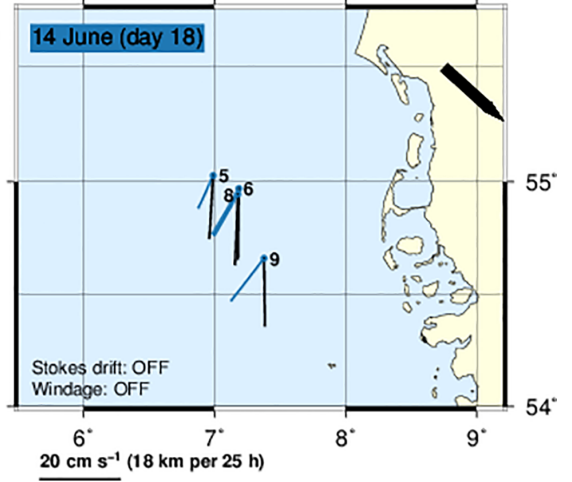

Figure 8. Continued from Fig. 7.

Note that after about day 12 both observations and simulations for the two drifters (nos. 6 and 8) are more or less plotted on top of each other (applies to Fig. 8c and $\mathrm{g}$, for instance, and various plots in the Supplement).

Days 15-16 (11-12 June): For a short time, the circulation returns to cyclonic orientation (Fig. 3). BSHcmod $+\mathrm{W}$ simulations greatly underestimate drift velocities to the north-west and tend to even cease on day 16 (Figs. 6 and $8 \mathrm{c}$ ). Due to low winds (from north-east or east), 


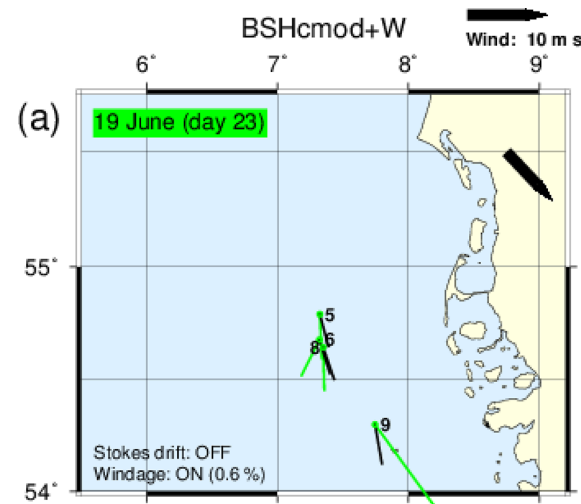

(e)
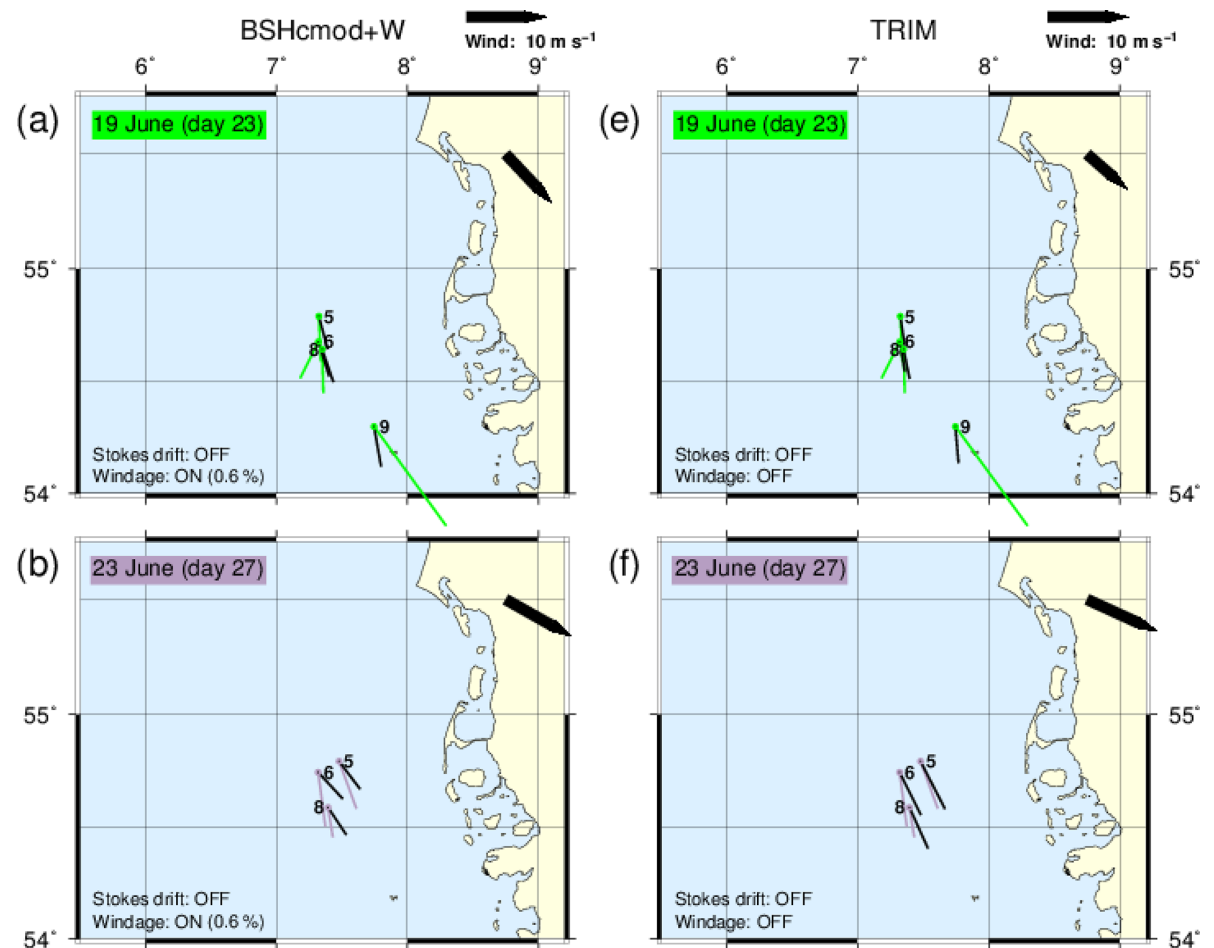

(f)
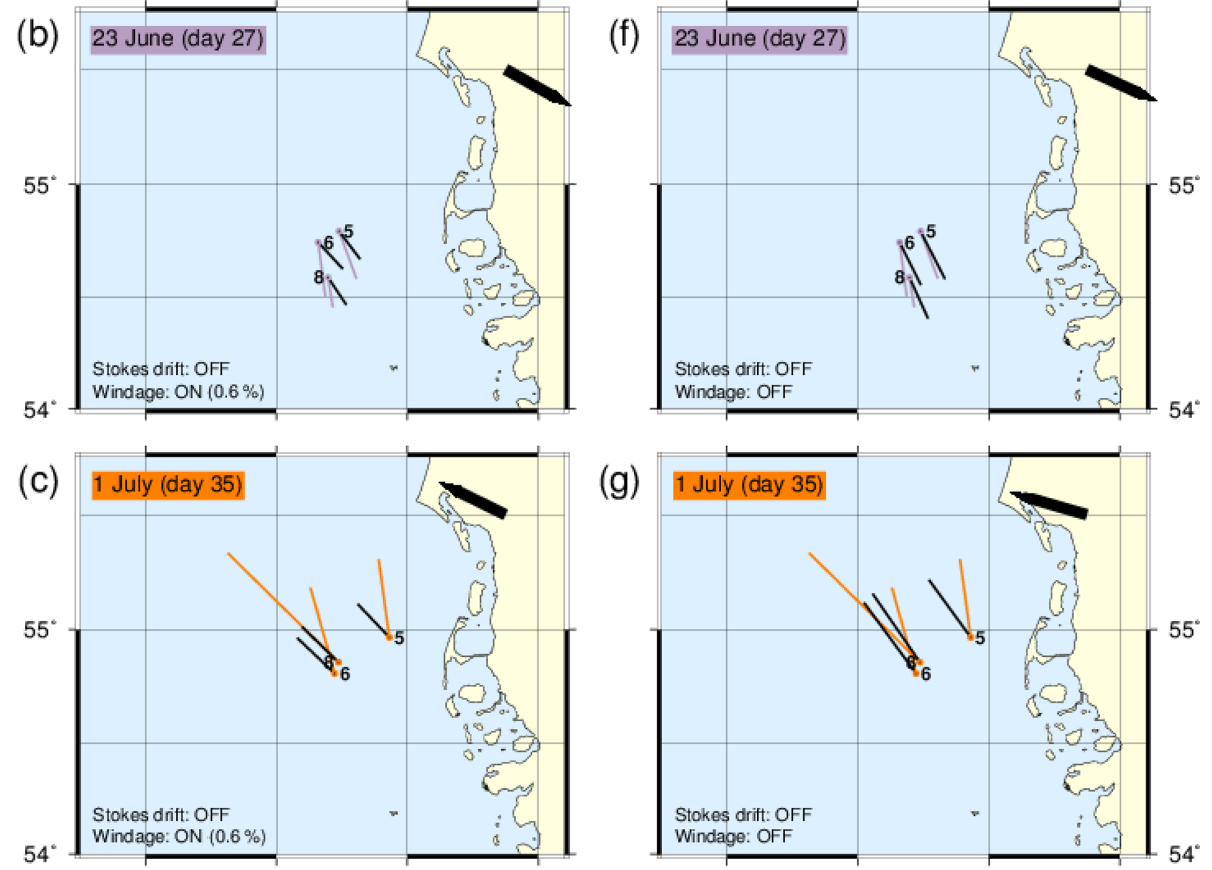

(g)
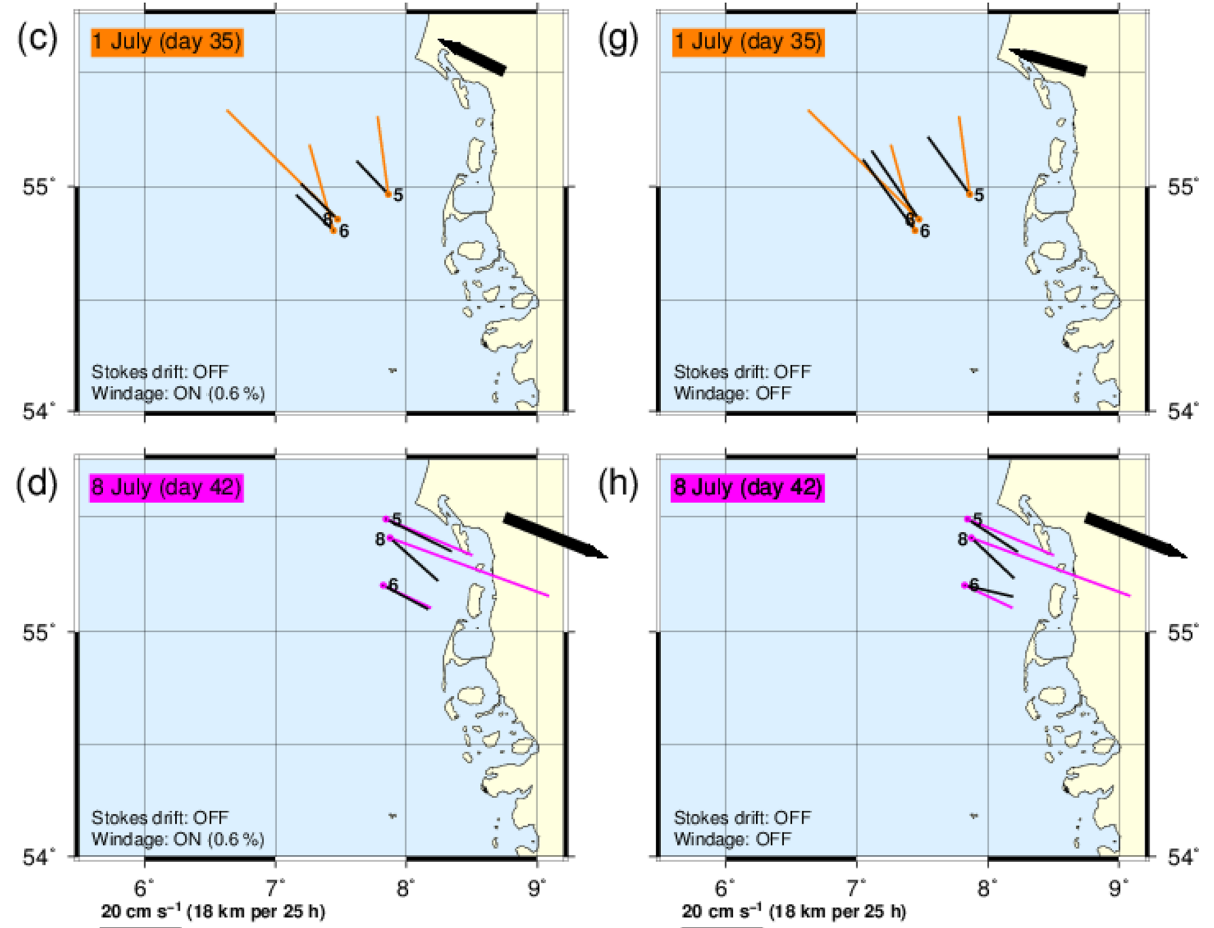

(h)

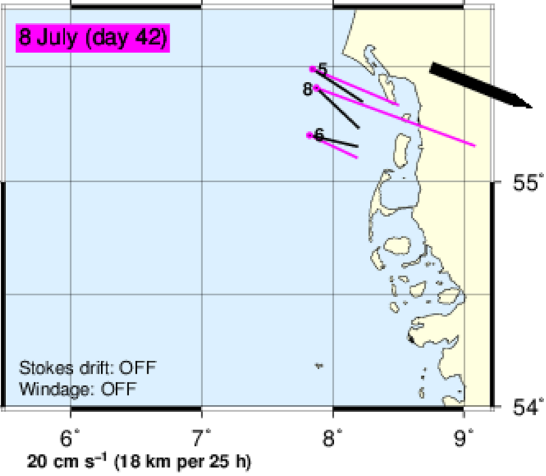

Figure 9. Continued from Figs. 7 and 8.

additional windage could not eradicate this deficiency. TRIM simulations perform slightly better (Fig. 8g).

Days 17-20 (13-16 June): During days 17-19, the circulation is anticyclonic, driven by north-westerly winds
(Fig. 3). Simulations based on either model consistently produce drift velocities that are markedly rotated to the left of observations (Figs. 8d, h and 10d).

On day 20, the wind direction turns to the south-west in BSHcmod or west in TRIM (Fig. 3); the residual 
circulation becomes cyclonic for 1 day. Under transitional conditions, directional errors are particularly high in TRIM (Fig. 10d).

Days 21-26 (17-22 June): Residual circulation gradually changes from anticyclonic to cyclonic (Fig. 3). During days 21-23, considerable errors in both BSHcmod $+\mathrm{W}$ and TRIM simulations resemble each other to a surprising degree (e.g. Fig. 9a and e). Except for drifter no. 9, drift directions are typically rotated to the left of observations (Fig. 10d). From about day 22 onward, drifter nos. 6 and 8 start separating again (Fig. 5). Expectedly, neither model reproduces sub-grid-scale differences in speed (day 22; SM3) or direction (day 23; Fig. 9a and e).

Starting on about day 22, fast movements mostly in line with prevailing wind directions (e.g. Fig. 9a and e) and greatly exceeding simulated counterparts (Fig. 6) suggest that drifter no. 9 experienced some problem with its drogue.

Days 27-28 (23-24 June): On day 27 (Fig. 9b and f), strong winds from the north-west give rise to southern transports. Substantial differences between speeds of neighbouring drifter nos. 6 and 8 (unresolved in simulations) imply a short period of their fast convergence (Fig. 5). $\mathrm{BSHcmod}+\mathrm{W}$ simulations greatly benefit from the inclusion of windage (Fig. 9b and SM2), while TRIM simulations are more consistent even without windage (Fig. 9f). On day 28, winds abate.

Days 29-33 (25-29 June): This is a period with variable wind directions. Drifter displacements are generally underestimated (Figs. 6 and 10a), observed northward transports (e.g. for drifter no. 8; Fig. 4e) are not reasonably reproduced based on BSHcmod $+\mathrm{W}$ (Fig. A2e) and even less based on TRIM (Fig. A4e).

Day 34 (30 June): Drifter nos. 6 and 8 converge quickly (Fig. 5), caused by a fast west-northwest movement of drifter no. 8, not shared by drifter nos. 5 and 6 (SM3). No model resolves these substantial differences.

Days 35-38 (1-4 July): Drifter nos. 5, 6 and 8 all move quickly into northern or north-western directions (Fig. 4). Largest drifter displacements occur on day 35 (see Figs. 9c, g and 6) with strong winds from the southeast. Drifter no. 8 moving faster and more aligned with wind direction than its companion drifters could possibly indicate problems with the drogue.

On day 36, TRIM (but not BSHcmod) assumes the wind to persist (Fig. 3 or SM3), which results in a substantial overestimation of drifter displacements (Fig. 10a). According to observations at Heligoland (Fig. 3), winds used by BSHcmod $+\mathrm{W}$ seem more realistic.
Under low wind conditions on day 37 , BSHcmod $+\mathrm{W}$ (to a lesser degree also TRIM) very much underestimates drift speeds (Fig. 6). On day 38, the process of drifter nos. 6 and 8 coming to rest is well reproduced in both models (SM3).

Days 39-41 (5-7 July): Freshening south-westerly winds strengthen a cyclonic circulation (Fig. 3). The extremely fast movement of drifter no. 8 is remarkable in reaction to this forcing (Figs. 4e and 6c). Simulations for drifter nos. 5 and 6 perform well, while the behaviour of drifter no. 8 cannot be reproduced.

Days 42-43 (8-9 July): The wind turning from south-west to north-west implies a fast transition from a cyclonic to an anticyclonic residual current regime (Fig. 3). Models perform well for drifter no. 6, while simulations for drifter no. 8 are again very poor (Figs. $6 c$ and 9d, h).

Days 44-53 (10-19 July): Only drifter nos. 5 and 6 are left; both of them are already located in coastal waters. Extra large differences between wind velocities used in BSHcmod and TRIM occur (Fig. 10b). Effects of a sudden reversal of the mean wind direction between days 50 and 51 are reasonably reflected in both models.

\section{Discussion}

The model validation study suggests the assumption that inclusion of either wind drag or Stokes drift compensates insufficient vertical resolution $(5 \mathrm{~m})$ of surface currents in archived BSHcmod output. Magnitudes of TRIM surface currents, representative of a layer of $1 \mathrm{~m}$ depth, were generally similar to those observed (Fig. 10a). In many cases, however, $25 \mathrm{~h}$ simulations based on BSHcmod $+\mathrm{W}$ outperformed those based on TRIM, in other cases (e.g. days 1316) TRIM simulations were in better agreement with observations (Figs. 8c, g or 10).

In several other studies (e.g. Gästgifvars et al., 2006; Kjellsson and Döös, 2012; De Dominicis et al., 2012), simulated marine surface currents were found to be too small, possibly also due to insufficient resolution of the marine surface layer. As a side effect, predictions may be particularly good when marine currents and winds are nearly parallel (Gästgifvars et al., 2006). The drift component most underestimated based on just BSHcmod Eulerian currents was a displacement towards the east, along the most frequent wind directions (compare Figs. 4 and A1). This deficiency could very effectively be remedied by adding direct effects of winds or waves. However, during periods when anticyclonic residual currents prevail (along with winds from the north-west, for instance), currents will generally not be in the direction of winds (e.g. day 18; Fig. 8d and h), unlike the situation with south-westerly winds driving a cyclonic circulation (e.g. day 3; Fig. 7a and e). Erroneous residual surface currents in 
(a)

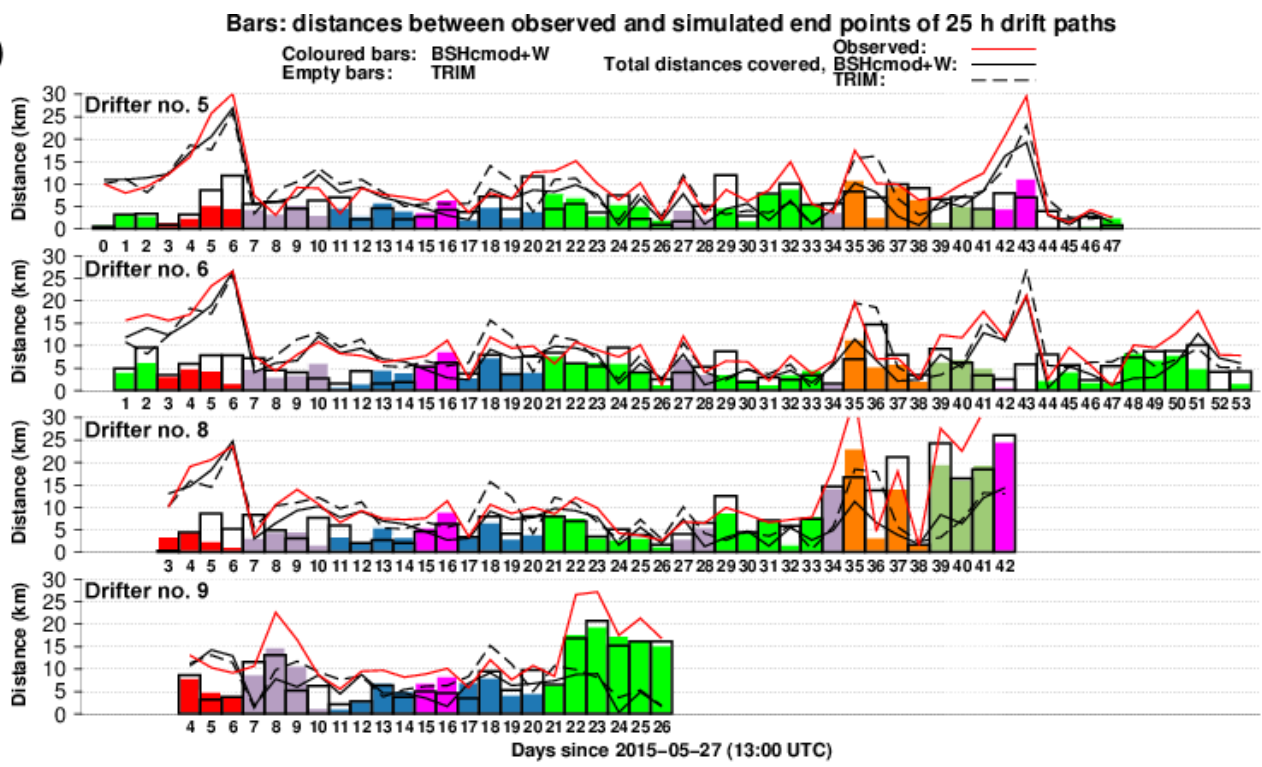

(b)

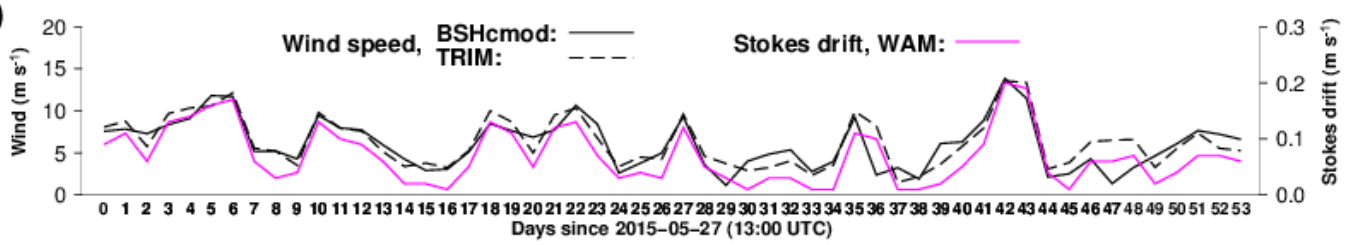

(c)

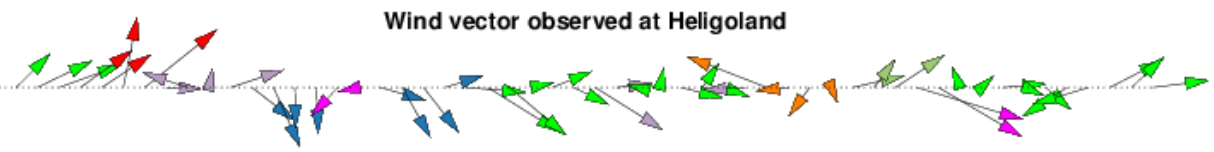

(d)

Rotation of simulations against observations (positive to the right)

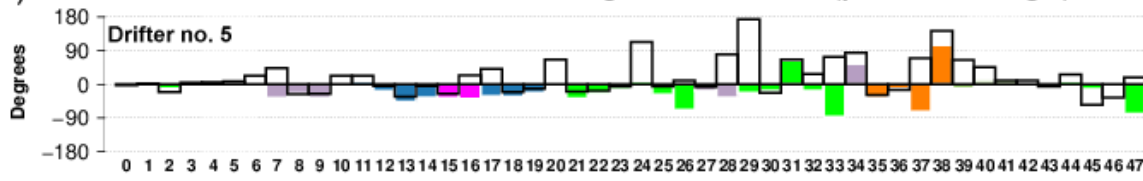

Drifter no. 6

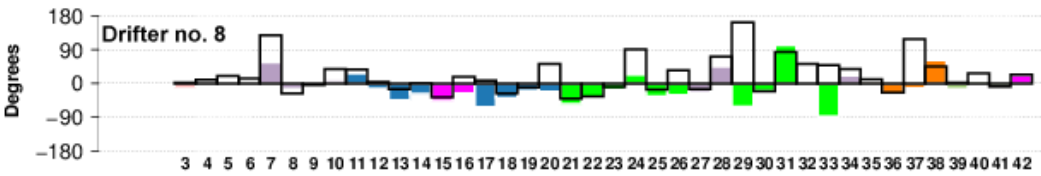

$\left.\begin{array}{rr}r 80 \\ 90\end{array}\right]$ Drifter no. 9

Figure 10. (a) Bars indicate distances between observed end points of $25 \mathrm{~h}$ drift paths and corresponding simulations based on either BSHcmod + W or TRIM. All drift errors, coloured and labelled in terms of days since 27 May (13:00 UTC), are assigned to the centre of the respective $25 \mathrm{~h}$ period. In addition, lines show total distances travelled. (b) Wind speeds used in the two models and surface Stokes drifts obtained from wave model WAM. Data were extracted for the central example location $\left(55^{\circ} \mathrm{N}\right.$ and $\left.7^{\circ} \mathrm{E}\right)$. (c) Heligoland winds, copied from Fig. 3. (d) Angles between observed and simulated tracer displacements. Throughout the figure, all values represent $25 \mathrm{~h}$ averages. 
(a) Model error: distance

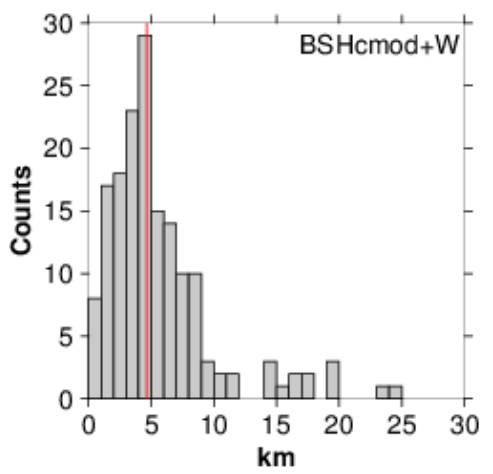

(c) Model error: angle

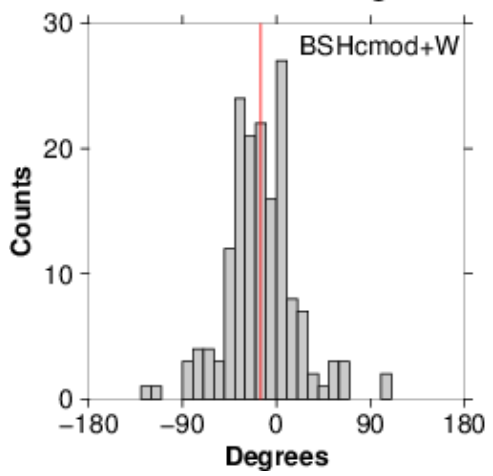

(b) Model error: distance

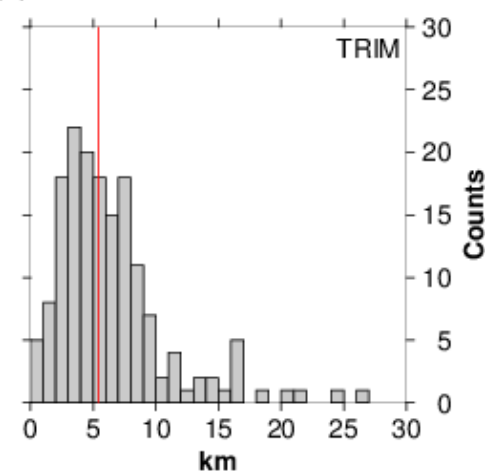

(d) Model error: angle

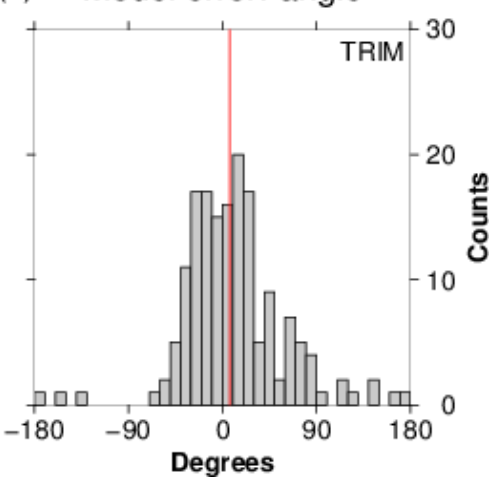

Figure 11. Distribution of model errors in $25 \mathrm{~h}$ drifter simulations. Histograms are based on 164 simulations in total for drifter nos. $5,6,8$ and no. 9. Referring to drift simulations based on BSHcmod + W and TRIM, respectively, panels (a, b) evaluate spatial separations shown in Fig. 10a. For the same set of 164 simulations, panels (c, d) evaluate directional errors from Fig. 10d. Red lines indicate median values (4.6 and $5.4 \mathrm{~km}$ in $\mathbf{a}, \mathbf{b} ;-15$ and $7^{\circ}$ in $\left.\mathbf{c}, \mathbf{d}\right)$.

the inner German Bight can therefore not always be fixed by simply adding windage or Stokes drift.

In both BSHcmod $+\mathrm{W}$ and TRIM simulations, drifter displacements were often rotated to the left of their observed counterparts, e.g. during days 13-23 (see Figs. 10d or 8d and h). A parametrization of wind-induced Ekman drift (Röhrs and Christensen, 2015) might be explored as a means to remedy such model deficiencies including lacking representation of the Coriolis-Stokes drift (Hasselmann, 1970; Polton et al., 2005) driven by ocean surface waves. Fig. 11 shows error distributions that combine all data from Fig. 10a and d, respectively. Median errors of drifter displacements are of the order of $5 \mathrm{~km}$ for both BSHcmod $(4.6 \mathrm{~km})$ and TRIM $(5.4 \mathrm{~km})$. BSHcmod $+\mathrm{W}$ tends to have negative directional errors (median value of about $15^{\circ}$ to the left of observations), while the median directional error for TRIM is about $7^{\circ}$ to the right. Negative deflections of BSHcmod $+\mathrm{W}$ simulations happen to coincide with what one would expect from a simple parametrization of windage (or Stokes drift) that neglects effects of Coriolis force. However, distributions in Fig. 11 combine simulations under very different wind conditions, and directional biases are not permanent. In many cases (e.g. day 18 in Fig. 8d and h), directional errors of the two simula- tions resemble each other. One must therefore be very careful to interpret shifted median values in terms of specific model deficiencies. Differences between Fig. 11c and d are probably not statistically significant, so we refrained from trying to incorporate and tune additional effects of Coriolis force.

Drifter nos. 5, 6 and 8 played a central role in this study because their trajectories overlapped for 40 days, enabling tentative conclusions regarding spatial scales that affected long- and short-term drifter displacements. Wind fields resolved in numerical models (and also corresponding fields of Stokes drift) tend to vary smoothly on a regional scale. A substantial impact of winds on surface currents may be one of the reasons why simulated trajectories resemble each other more than corresponding observations. However, also observed drifter paths show similarities that point to the impact of large-scale forcing.

Due to bathymetric constraints and different scales of relevant processes, spatial variability of marine currents tends to be higher than that of wind fields (Röhrs et al., 2012). However, our study did not show clear effects of the higher resolution in BSHcmod regarding either space ( $900 \mathrm{~m}$ compared to $1.6 \mathrm{~km}$ in TRIM) or time (15 min compared to $1 \mathrm{~h}$ in TRIM). Both TRIM and BSHcmod are unable to reproduce the spe- 
cific behaviour of drifter no. 7 during days $7-11$, for instance (Figs. 4d, 7 and 8). This could suggest that some relevant aspects of near-shore transports are not properly represented in both models. Surprisingly small effects of resolutions in both space and time on the metrics for Lagrangian predictability were also reported by Huntley et al. (2011).

Drifters will separate even if they are released from about the same location. Ohlmann et al. (2012) start with $\mathcal{O}(5-$ $10 \mathrm{~m}$ ) initial separations to resolve initial non-local dispersion with exponential growth of the mean square pair separation, driven by eddies larger than the distance between the two drifters. In the present field experiment, simultaneous deployments of drifter nos. 2 and 3 were originally intended to study an example of drifter dispersion. The two drifters, both tracked over 3.7 days, stayed very close together for some time until they abruptly started to separate. However, this separation might have been triggered by an unobserved interaction with the research vessel. Due to such concerns, drifter nos. 2 and 3 were excluded from the present analysis.

Fortunately, drifter nos. 6 and 8 offered another opportunity to estimate predictability of drift trajectories. The minimum distance of only $800 \mathrm{~m}$ qualified the two drifters as a "chance pair" (e.g. Döös et al., 2011). Note, however, that drifter nos. 6 and 8 were of different types (see Table 1) so that relative dispersion measured may not necessarily reflect diffusivity of the flow. On the other hand, the two drifters travelling jointly for about 10 days in a sense justifies the assumption that consequences of different designs were not essential. Also Fig. 6b and c provide no evidence for systematic differences in observed drift speeds during the period of interest.

From the perspective of a model with either $900 \mathrm{~m}$ (BSHcmod) or $1.6 \mathrm{~km}$ (TRIM) grid resolution, the locations of drifter nos. 6 and 8 almost coincided for about 10 days. The subsequent separation rate of about $3 \mathrm{~km} \mathrm{day}^{-1}$ (according to visual inspection of Fig. 5) indicates a lower bound of prediction uncertainty under these specific conditions. An independent second estimate can be obtained considering the period when the two drifters converged (days 8-11). Assume that modelling was undertaken to determine where an item collected on day 11 came from. Looking 4 days back in time, the two drifters (nos. 6 and 8) have separated by about $20 \mathrm{~km}$, so that the uncertainty estimate (about $5 \mathrm{~km} \mathrm{day}^{-1}$ ) even exceeds the above value. However, the separation rate is still much lower than that reported by Huntley et al. (2011, their Fig. 3) under open ocean conditions near the Kuroshio current, considering a similar constellation with two drifters that separate after staying close for a couple of days. A wide spectrum of typical separation rates in different regions worldwide provided by Barron et al. (2007) also shows systematically larger values.

Error bounds estimated from drifter convergence/divergence will combine with model deficiencies that at least theoretically could be eliminated by model improvement or calibration. However, the above error estimates roughly fit into the general range of simulation errors found in this study (Fig. 11a and b). Ohlmann et al. (2012) tried to reproduce observed drifter trajectories with a Lagrangian stochastic model based on Eulerian background velocities derived from high-frequency (HF) radar observations interpolated to a regular $2 \times 2 \mathrm{~km}^{2}$ grid. Substantial discrepancies exceeding the expected level of HF radar measurement errors were found in occasional periods. On average, the separation between corresponding centres of gravity was found to be about $5 \mathrm{~km}$ after $24 \mathrm{~h}$, a value that compares well with estimations from the present experiment. It remains as an open question whether the quality of predictions would be better with HF radar observations replacing output from numerical models. Ullman et al. (2006) found skills in predictions based on currents from either a circulation model or HF radar comparable. Both Ullman et al. (2006) and Ohlmann et al. (2012) used hourly average velocities from HF radar observations, i.e. the same temporal resolution as in the present study. Higher-resolution (e.g. 20 min; Horstmann et al., 2017) measurements of currents could possibly better capture short-term fluctuations and enhance variability in drift simulations.

According to Koszalka et al. (2009) and Döös et al. (2011), "chance pairs" should possibly be distinguished from pairs of drifters intentionally launched together, because their behaviour may depend on specific hydrodynamic conditions. An interesting question is what characterizes the 10-day period when drifter nos. 6 and 8 stayed close together. The drifter convergence (days 7-10) coincided with the transition from a cyclonic to an anticyclonic residual current circulation (Fig. 3). The anticyclonic regime forced by winds from mainly the north-west dominated days (11-20), except for a short episode (days 14-16) with very low winds and a circulation returning to the cyclonic orientation for about 1 day. Drifter nos. 6 and 8 started separating again when residual currents gradually returned to an either indifferent or cyclonic circulation, a process probably best represented in the time series of $\mathrm{PC}_{1}$ in Fig. 3. Thus, it seems that both convergence and divergence of the two drifters coincided with reorientations of the hydrodynamic regime.

The present data are insufficient for a discussion of to which extent the drifters' observed responses to changing winds and residual currents depend on drifter location. Based on model simulations, however, there are promising techniques to better describe regions within which separation for drifters can be expected. Identification of Lagrangian coherent structures (LCSs) is a field that developed recently (e.g. Shadden et al., 2009). Huhn et al. (2012) applied the method to identify transport barriers for drifters in an estuary; Peacock and Haller (2013) discuss how such techniques could be used for optimizing drifter deployment in the sense of maximizing their dispersion. Olascoaga et al. (2013) employed LCSs to illustrate how mesoscale circulation shapes nearsurface transports in the Gulf of Mexico. 
A couple of different processes can be relevant for an exchange of energy and momentum between surface waves and underlying mean currents (Smith, 2006). Under open sea conditions, probably the most important process affecting near-surface drifters is the Stokes drift which arises when backward motions beneath the troughs of surface gravity waves do not fully compensate forward motions beneath the crests. However, a key observation from our simulation experiments is that for surface drifters the inclusion of an explicitly simulated Stokes drift did not produce an added value beyond a simple parametrization of wind drag in terms of $10 \mathrm{~m}$ winds. According to Fig. 10b, wind speeds used as forcing for either TRIM or BSHcmod are both highly correlated with Stokes drifts calculated with wave model WAM (based on the same wind hindcast also used as forcing for TRIM). This similarity agrees with results reported by Drivdal et al. (2014, their Fig. 7), for instance.

From experimental data, Röhrs et al. (2012) estimated Stokes drift to be about twice as large as effects of direct wind drag. However, as the roles of direct wind drag and Stokes drift are difficult to disentangle, we did not conduct experiments with mixtures of the two processes. For the factors $\alpha$ or $\beta$, we chose in Eq. (1), drift components from either windage or Stokes drift were similar most of the time (Fig. 6). Validating modelled wave effects based on four surface drifters deployed near the Grand Banks (Newfoundland), Tang et al. (2007) considered both processes in combination. They also found simulated Stokes drift to be linearly related to wind velocities, so that it seems difficult to decide whether the approximately $21 \%$ decrease of separation between modelled and observed trajectories after 1 day are really attributable to Stokes drift effects. According to Breivik and Allen (2008), the impracticality to separate Stokes drift effects from an empirically parametrized direct wind drag is a major reason why Stokes drift is neglected even in most operational search and rescue modelling systems, where a realistic assessment of existing uncertainties and their origin is of utmost importance.

Tang et al. (2007) found Stokes drift to be about $1.5 \%$ of wind speed; Li et al. (2017) report a value of $1.6 \%$. These values agree with the ratio $(0.3 / 20)$ of the scales annotated on the two $y$ coordinates in Fig. 10b. For low wind conditions, the relative importance of Stokes drift decreased (again in agreement with the results of Tang et al., 2007), but in these cases the overall contributions from winds and waves are small anyway.

In particular, growing young wind seas forced by local winds typically produce strong surface Stokes drifts that decline fast with depth (e.g. Röhrs et al., 2012). Breivik et al. (2016) developed an approximate method to efficiently calculate this near-surface shear, underestimated by the common assumption of a monochromatic profile. Based on these formulas, Röhrs and Christensen (2015) calculated in the context of a drifter experiment in the Barents Sea and Norwegian Sea that an average Stokes drift of $8.9 \mathrm{~cm} \mathrm{~s}^{-1}$ at the surface contrasted with an average of $3.7 \mathrm{~cm} \mathrm{~s}^{-1}$ at $1 \mathrm{~m}$ depth. For the present study, we neither applied theoretical profiles nor conducted an in-depth model calibration. However, in the light of the above numbers, the $50 \%$ factor $\alpha$ in Eq. (1) we chose for BSHcmod $+\mathrm{S}$ seems to be a reasonable value for drifters representing a surface layer of about $1 \mathrm{~m}$ depth. Vagueness of the factor corresponds with that of the $0.6 \%$ windage factor $\beta$ used in BSHcmod $+\mathrm{W}$. Given the limited data, in both cases, even most careful calibration would not lead to robust estimates. The criterion we applied for selecting $\alpha$ or $\beta$ is that the overall eastward displacement of a drifter's location should roughly agree with that observed. A convincing confirmation of our selection was that the strength factors we chose worked consistently well for all drifters.

Similarity between simulations with either wind drag or Stokes drift (see SM4) is an implicit consequence of how parameters were chosen. According to Fig. 6, a period with major differences between contributions from either windage or Stokes drift occurs during days 30-34, when indeed simulations based on BSHcmod $+\mathrm{W}$ and $\mathrm{BSH}$ cmod $+\mathrm{S}$, respectively, diverge (see Figs. A2 and A3). According to Fig. 4b, however, results from model version BSHcmod $+\mathrm{W}$ seem to be more realistic. It is interesting to see that also TRIM simulations are particularly wrong in this period, producing, e.g. for drifter no. 5 transports to the south-east (Fig. A4b), when in reality the drifter moved in a north-east direction (Fig. 4b).

Figure 12 compares magnitudes of observed and simulated drift speeds on an hourly basis, referring to trajectories of drifter nos. 5 and 6 during days 0-17 (see SM5 in the Supplement for corresponding full time series). As in Fig. 6, all simulated velocity components were specified at observed rather than simulated drifter locations (i.e. no drift simulation was performed), so as to avoid the problem of spatial separation between simulations and observed counterparts. Observed and simulated drift speeds agree surprisingly well at least during approximately days $0-12$. Nearly perfect agreement for one drifter sometimes coincides with discrepancies for the other, a possible manifestation of sub-grid-scale processes (see observations at the beginning of day 5 , for instance).

Together with total drift speeds, Fig. 12 also shows magnitudes of simulated windage and Stokes drift. During most of the time, these two drift components are of similar size. More short-term pulses of Stokes drift can be discerned on days 5-6. Generally, however, contributions from both wind and waves are smooth. A removal of compensating tidal effects by averaging enhances visibility of the contributions of winds or waves (see Fig. 6). Note that, due to vectors having different directions, differences between total drift speeds and contributions of windage do not directly translate into magnitudes of mean Eulerian currents. For instance, a non-zero windage effect may be offset by an opposed Eulerian current. For BSHcmod + W simulations of drifter no. 5 , we found average magnitudes of hourly Eulerian currents to be about $0.27 \mathrm{~m} \mathrm{~s}^{-1}$ and corresponding values for 
windage about $0.043 \mathrm{~m} \mathrm{~s}^{-1}$. The resulting relative magnitude of $16 \%$ roughly agrees with what Röhrs et al. (2012) found for Stokes drift. According to data from an experiment in northern Norway, Stokes drift amounted to about $20 \%$ of the mean Eulerian currents.

In Fig. 12, both observations and simulations show regular intermittent patterns in connection with tidal cycles. Variations of maximum drift speeds indicate that movements along different branches of tidal ellipses have components that are alternately oriented in the same or opposite direction of a superimposed non-tidal drift component. This nontidal drift is possibly but not necessarily related to wind effects. On days 13 and 14, such non-tidal drift manifests itself more in simulations than in observations, while during days 15 and 16 alternating drift speed maxima are more pronounced in observations (in particular for drifter no. 6). According to Fig. 6, BSHcmod $+\mathrm{W}$ underestimates residual drift speeds for all four drifters tracked at that time. A fast displacement of drifter no. 6 to the north-west can be discerned from Fig. 4c. All models fail to reproduce this movement (see Fig. A2c, for instance). Considering the small values of windage and the even smaller of Stokes drift (wind directions allow for only small fetches over the open sea), tuning these effects cannot substantially improve simulations.

Remember that Stokes drift and windage were calculated offline and added to the Eulerian currents after the model had been integrated and the fields stored. Lacking success of this approach is not to say that deficiencies of drifter simulations are not related to wind conditions. The problem around days $15-16$, for instance, occurs under non-stationary wind directions that affect also the orientation of the residual current regime (Fig. 3). Changes of wave-induced forcing of the ocean, including sea-state-dependent momentum flux and Stokes drift (Staneva et al., 2017), affect water level, high and low water times and therefore also ocean currents.

Röhrs et al. (2012) warn that implementing Stokes drift as a simple additive component of drift velocity, parameterized in terms of wind forcing, can be inconsistent (i.e. violate conservation of both momentum and energy) if Eulerian currents were simulated without taking into account the reservoir of wave momentum and energy. In the present study, the exchangeability of Stokes drift and wind drag indicates that the role of waves as a reservoir of momentum was not relevant at least during the period considered. One reason for this could be that due to limited fetches the North Sea is less swell dominated than other Nordic Seas (Semedo et al., 2015).

Two crucial and outstanding questions are (a) whether the drifters' behaviours are representative of surface currents and (b) if it justifiably can be assumed that all drifters maintained their ideal drift properties over the whole period they were tracked. Drifter trajectories may reflect a specific exposure to winds and waves, well illustrated by the experiment reported by Röhrs et al. (2012). Edwards et al. (2006) suggested corrections to improve trajectory simulations when wind errors and characteristics of the specific drifters deployed are known. However, for the present study, a tentative positive answer to the first question could be given based on the reasonable correspondence between the magnitudes of observed tracer displacements and their counterparts simulated based on just TRIM Eulerian surface currents (see Fig. 10a). On the other hand, Poulain et al. (2009) estimated a higher downwind slippage of about $1 \%$ of the wind speed for undrogued SVP (Surface Velocity Program) drifters. In the context of an oil-drift study, Price et al. (2006) deployed CODE (Coastal Ocean Dynamics Experiment)-type drifters drogued in such a way that they were supposed to capture the upper $1 \mathrm{~m}$ layer velocities. Referring to a report by Niiler et al. (1997); Price et al. (2006) estimated for these drifters slip velocities of the order of $0.03 \mathrm{~m} \mathrm{~s}^{-1}$. In BSHcmod $+\mathrm{W}$, such velocity would match the parametrized wind drag at a wind speed of $5 \mathrm{~m} \mathrm{~s}^{-1}$. Like contributions from wind drag, the estimated downwind slippage of drifters is supposedly much smaller than shortterm drift velocities in a tidally dominated regime but may nevertheless have considerable impacts on drifter displacements in the long run. Fully disentangling effects of wind drag on water masses and drifters, respectively, seems hardly possible.

Answering the second question is again difficult. The joint analysis of drifter positions and displacements in this study gave at least some indications for possible non-ideal drifter behaviour. A period of extreme velocities far beyond what models predict occurs for drifter no. 9 at the end of its journey (days 22-26; Figs. 6d and 9a and e). These high velocities result in a clear separation of drifter no. 9 from the formerly concentrated group of drifters. Probably more central for the present study is the behaviour of drifter no. 8. From day 34 onward, drifter no. 8 showed a tendency to move faster than the neighbouring drifter nos. 5 and 6 (e.g. days 34-35, day 37 or days 39-42; Fig. 6). Strikingly, in these cases, drifter no. 8 tended to move into directions that are more parallel to prevailing winds (see SM1). This latter observation also applies to the aforementioned behaviour of drifter no. 9 .

Possible reasons for the deviant behaviours of drifter nos. 8 and 9 can only be speculated. The simplest explanation would be that the different types of the two drifters (and of drifter no. 7, which also showed a very fast movement at the end of the time period it was tracked) distinguishes them from other drifters deployed (Table 1). However, this explanation is not in accord with the fact that problems did not persist throughout the whole observational period. The special behaviour of drifter no. 9 after about day 22 coincided with its entering a more southern region of the German Bight (Fig. 9a and e). For this region, Port et al. (2011) identified a higher variability of surface currents, less correlated with wind conditions, which would imply that introducing either Stokes drift or an additional wind drag could probably be a less promising approach for model improvement. However, still the most probable explanation for the mismatch of observations and corresponding simulations is that the drifter experienced problems with its drogue. Unfortunately, drifters 

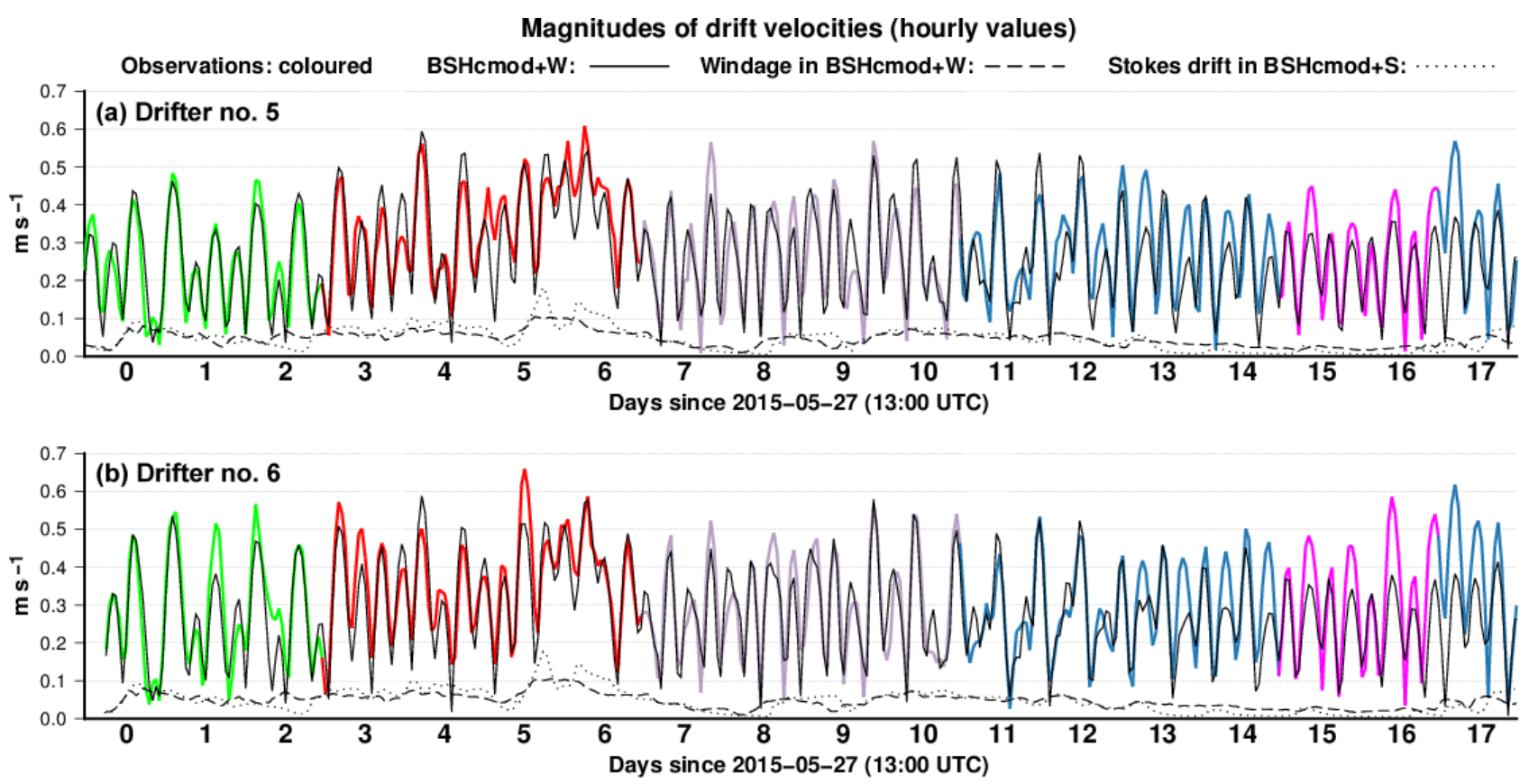

Figure 12. Magnitudes of drift velocities on an hourly basis, considering drifter nos. 5 (a) and 6 (b). As in Fig. 6, magnitudes of observed velocity vectors (coloured) are compared with simulations based on BSHcmod + W. In addition, magnitudes of windage (in BSHcmod + W) and Stokes drift (in BSHcmod + S) are shown. All model values are specified from either atmospheric or marine fields interpolated to observed (not simulated) drifter locations. For full time series, see the Supplement (SM5).

had no drogue presence sensor and could also not be collected at the end of their journey to check the conditions of the devices.

\section{Conclusions}

Trajectories of six surface drifters deployed in the German Bight were compared with corresponding offline simulations based on hydrodynamic data from two independent models. Successful simulations based on BSHcmod currents archived for a $5 \mathrm{~m}$ depth surface layer needed inclusion of extra wind (or wave) effects, which was not the case for simulations based on TRIM currents for a $1 \mathrm{~m}$ depth surface layer. This suggests the assumption that the extensions in BSHc$\bmod +\mathrm{W}$ or $\mathrm{BSH}$ cmod $+\mathrm{S}$ primarily acted to compensate insufficient vertical resolution in archived data. There was no convincing evidence that the drifters deployed experienced an appreciable direct wind drag. In a similar way, Ullman et al. (2006) attributed a bias of trajectories predicted based on HF radar currents not to a drifter leeway but rather to the fact that effective depth of HF radar measurements exceeded that of surface layer drifters.

On the other hand, it is striking that often errors in simulations based on TRIM and BSHcmod $+\mathrm{W}($ or BSHcmod $+\mathrm{S})$ closely resembled each other (e.g. day 8 - see Fig. 7 d and h; or day 18 - see Fig. $8 \mathrm{~d}$ and h). This points to problems shared by both models, explanation of which probably requires anal- yses considering also other aspects of hydrodynamic model output.

The present study focused on a synoptic assessment of (mainly four) drifter trajectories overlapping in time. Expectedly, differences between synchronous drift trajectories were much larger in observations than in simulations, due to unresolved sub-grid-scale processes. Simulated fields of wind (not including sub-grid-scale weather phenomena and gustiness as important drivers for drifter dispersion) and Stokes drift are even more smooth than simulated current fields. Small-scale model data misfits can therefore obviously not be remedied by employing windage or Stokes drift.

Although the small number of drifters does not enable an in depth analysis, it seems that major deficiencies of simulations often manifest themselves under low or moderate wind speeds. For instance, data from days 7 to 9 (see panels in Fig. 7) suggest that simulations underestimate currents in coastal areas at that time. Insufficient resolution of intertidal areas could be one aspect contributing to this model deficiency. Also, on days 15 and 16, observed drifters moving much faster than simulated (Fig. 6) coincides with low wind conditions (e.g. Fig. 8c and g). However, all instances also correspond with changes in wind conditions and transitions between different residual current regimes (Fig. 3).

On an hourly basis, contributions from windage in BSHcmod $+\mathrm{W}$ are often much smaller than discrepancies between simulated and observed drifter velocities (Fig. 12 or SM5), in particular under low wind conditions. When averaging over 
tidal cycles, relative contributions from wind forcing increase (Fig. 6). However, even small systematic errors in the simulation of oscillating tides might possibly give rise to erroneous residual current components similar in size to the contributions from windage. A finding that needs further analysis is whether near-shore residual currents underestimated in simulations indicate such inaccuracies in regions where tides increase with decreasing water depth.

This study did not substantiate benefits from including Stokes drift simulated offline. Directions of winds and waves coincided most of the time and effects of Stokes drift on surface currents could successfully be mimicked in terms of additional windage. In TRIM, such effects seemed already sufficiently parametrized as part of momentum transfer from the atmosphere to marine currents. When winds quickly abate, increase or turn, waves adjust with a time lag, needing a certain fetch to fully develop. Although in these cases the different roles of winds and waves could be more marked, in the present study errors in atmospheric or marine circulation modelling seemed predominant. Nevertheless, fully coupled modelling of currents and waves (Staneva et al., 2017) could probably improve simulated surface currents, given that the vertical resolution is fine enough. It must also be kept in mind that the present study did not include any extreme events.

The incident of two drifters converging quickly and separating about 10 days later provided evidence that at least in some situations an unavoidable increase in prediction uncertainty would be of the order of $3-5 \mathrm{~km} \mathrm{day}^{-1}$, regardless of however sophisticated a model used might be. Further studies would be needed to substantiate this finding in terms of its representativity and possible dependence on specific locations or atmospheric conditions. The observed separation rate happened to roughly agree with the average magnitude of simulation errors we identified. More experiments would help identify the way to go for further model improvements.

Data availability. The raw data of observed drifter locations are freely available from Carrasco and Horstmann (2017). Results of the PCA of residual currents are freely accessible at Callies (2016). 
Appendix A: Full sets of BSHcmod and TRIM simulations

In this Appendix, we present simulated counterparts of all observed trajectories shown in Fig. 4. The four different model setups considered are simulations based on BSHc$\bmod ($ Fig. A1), BSHcmod $+\mathrm{W}$ (Fig. A2), BSHcmod $+\mathrm{S}$ (Fig. A3) and TRIM (Fig. A4). For all figures, the underlying data are provided in the Supplement. 
(a) BSHcmod, simulation drifter no. 1

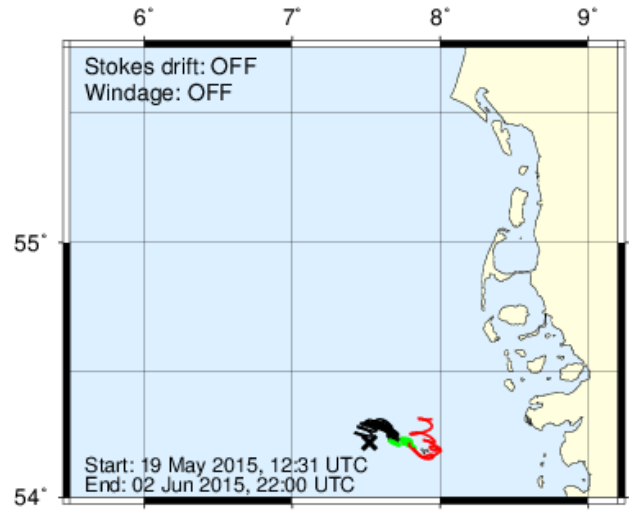

(c) BSHcmod, simulation drifter no. 6

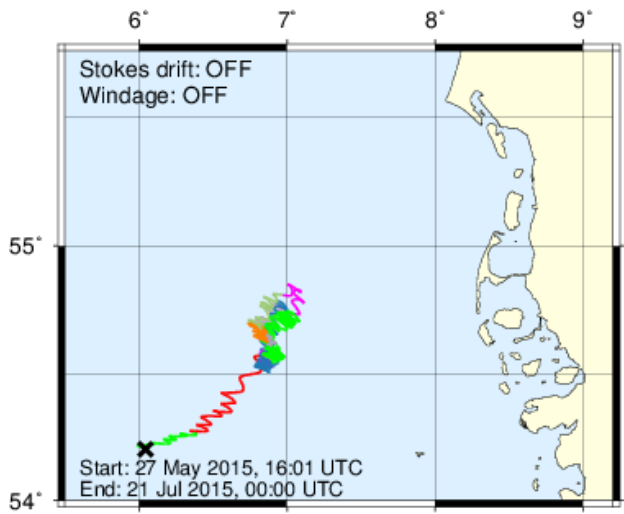

(e) BSHcmod, simulation drifter no. 8

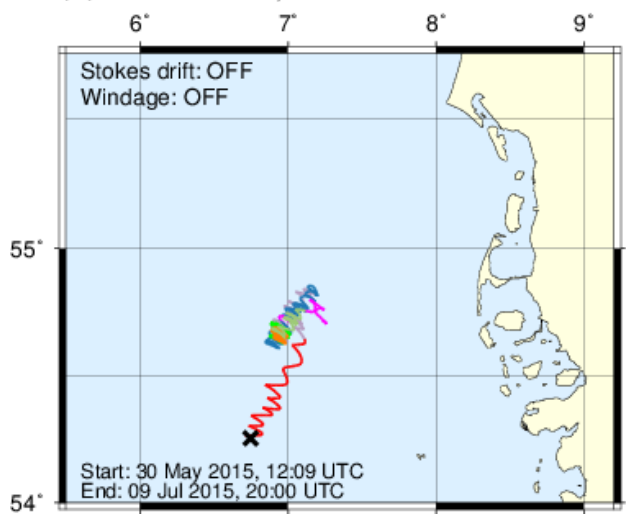

(b) BSHcmod, simulation drifter no. 5

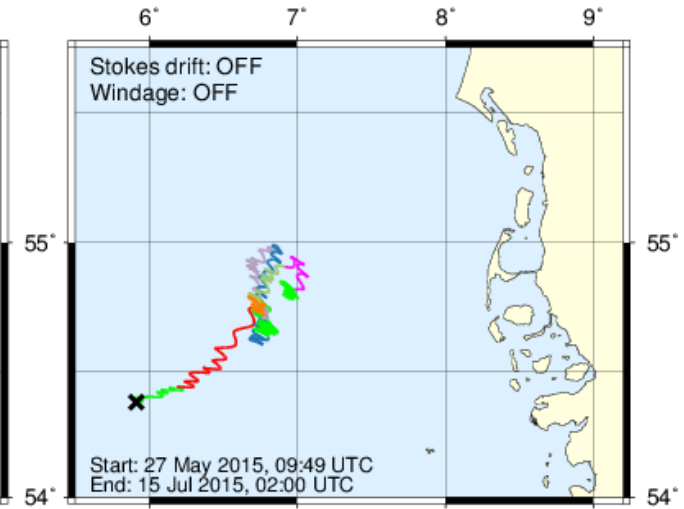

(d) $\quad$ BSHcmod, simulation drifter no. 7

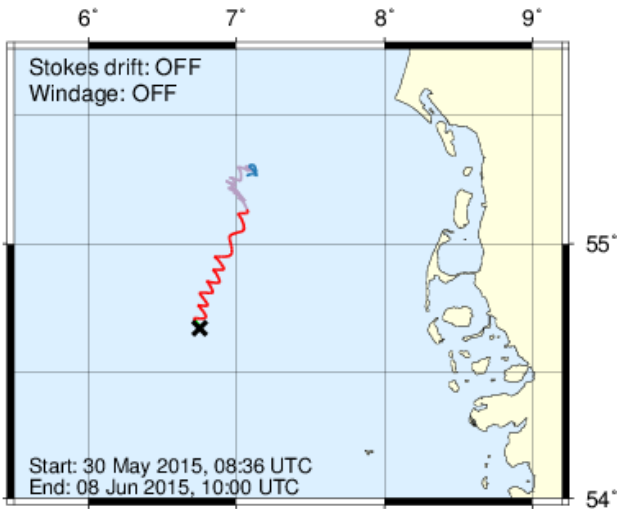

(f) BSHcmod, simulation drifter no. 9

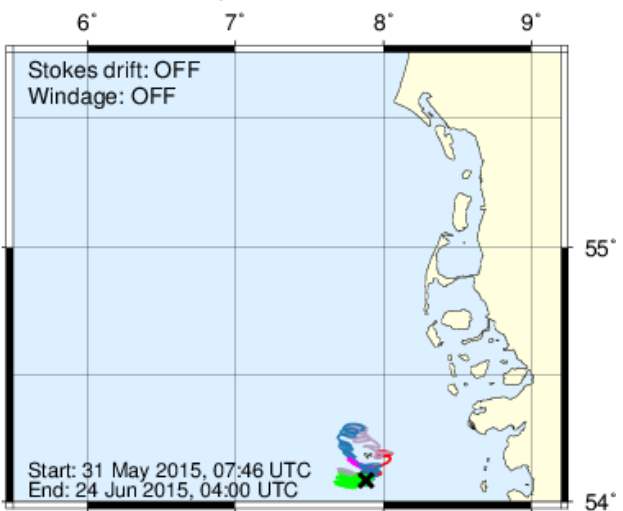

$-8-6-4-2024 \quad 6 \quad 81012141618202224262830323436384042444648505254$

Days since 2015-05-27-13:00 UTC

Figure A1. Simulations based on BSHcmod top-layer currents, disregarding extra effects of winds or waves. Black crosses indicate locations where simulations were started. 
(a) BSHcmod $+\mathrm{W}$, simulation drifter no. 1

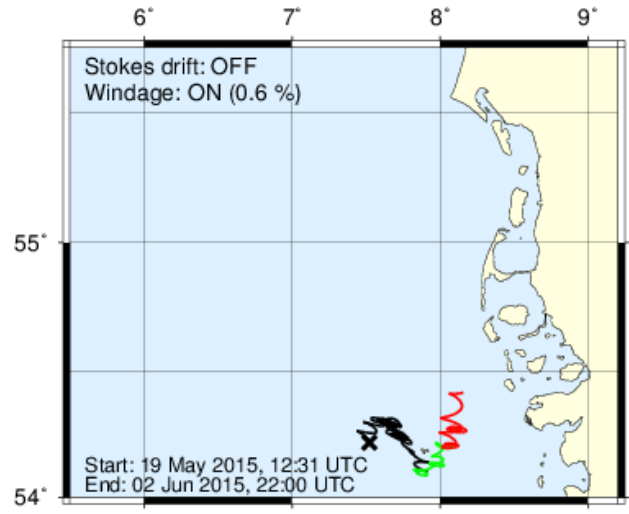

(c) BSHcmod+W, simulation drifter no. 6

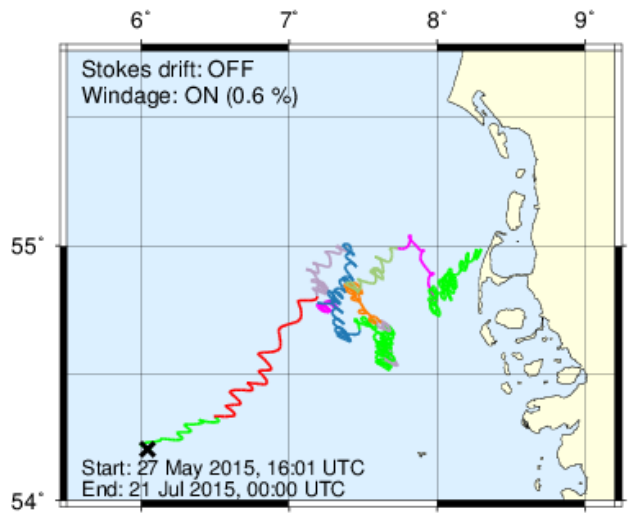

(e) BSHcmod+W, simulation drifter no. 8

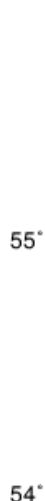

(b) BSHcmod+W, simulation drifter no. 5

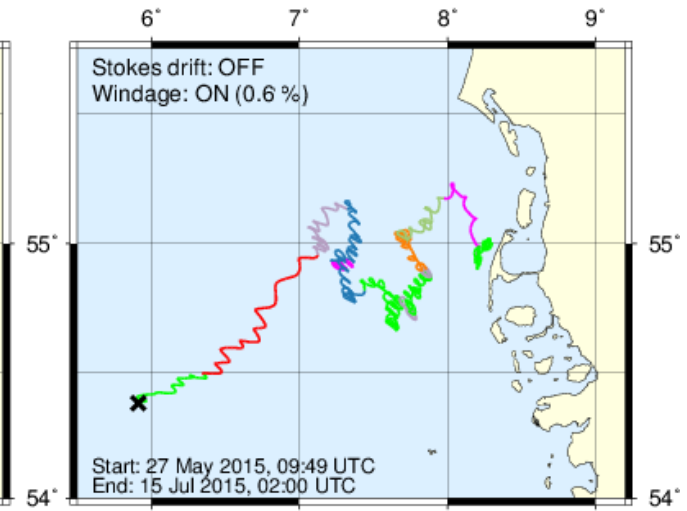

(d) BSHcmod + W, simulation drifter no. 7

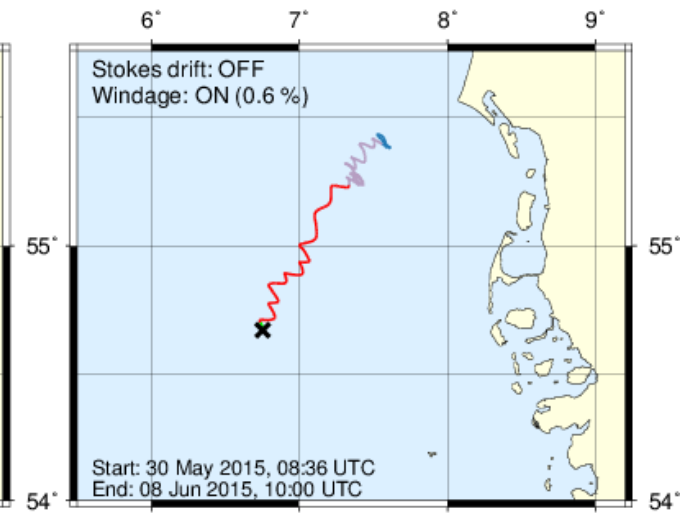

(f) BSHcmod+W, simulation drifter no. 9

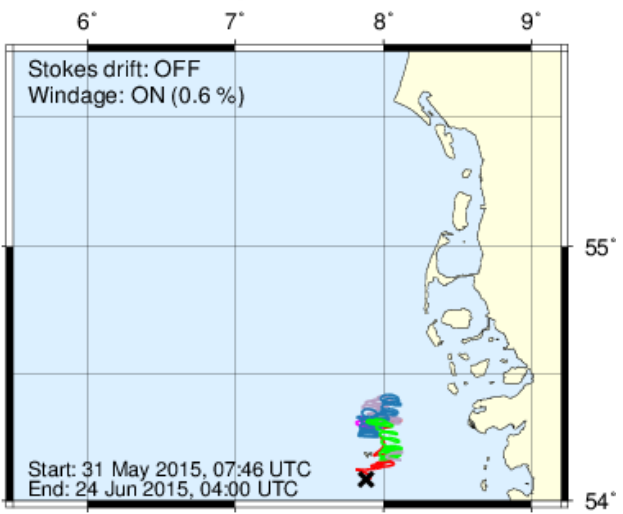

$-8-6-4-2024 \quad 6 \quad 81012141618202224262830323436384042444648505254$

Days since 2015-05-27-13:00 UTC

Figure A2. Simulations based on BSHcmod top-layer currents plus $0.6 \%$ of $10 \mathrm{~m}$ wind velocity (BSHcmod $+\mathrm{W})$. Black crosses indicate locations where simulations were started. 
(a) BSHcmod+S, simulation drifter no. 1

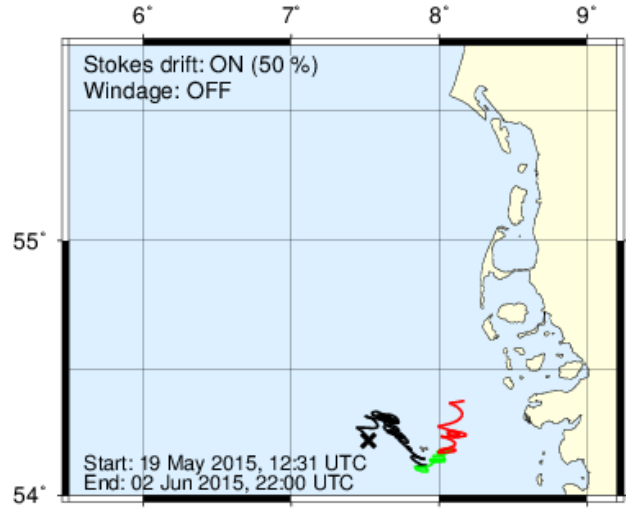

(c) BSHcmod $+\mathrm{S}$, simulation drifter no. 6

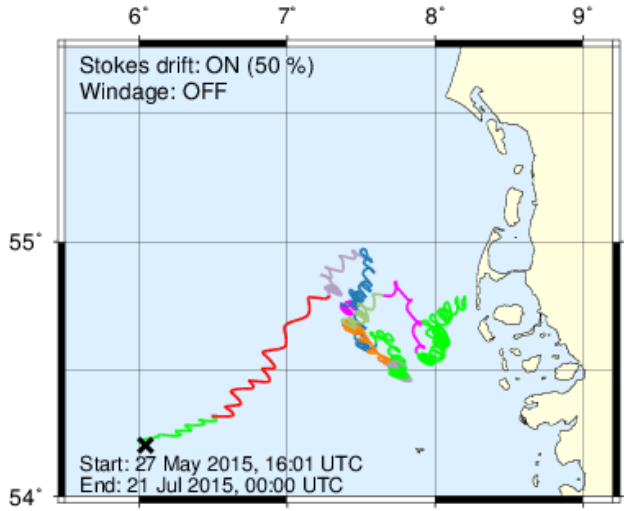

(e) BSHcmod+S, simulation drifter no. 8

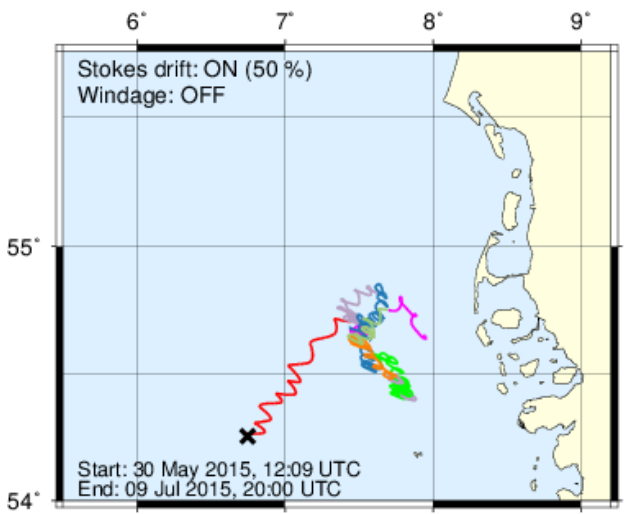

(b) BSHcmod+S, simulation drifter no. 5

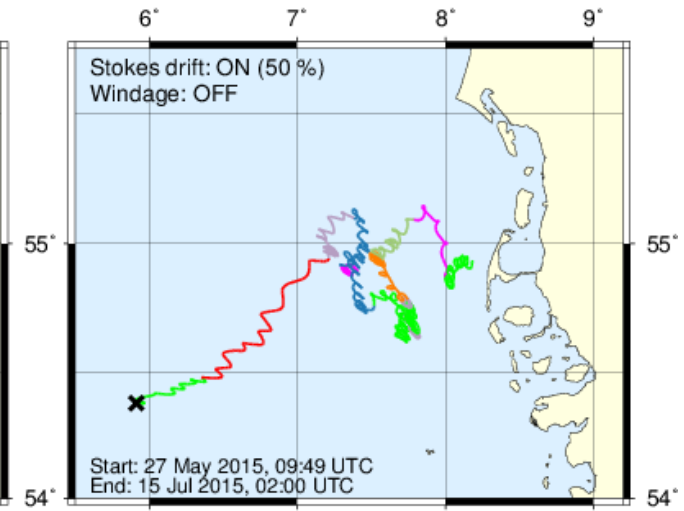

(d) BSHcmod+S, simulation drifter no. 7

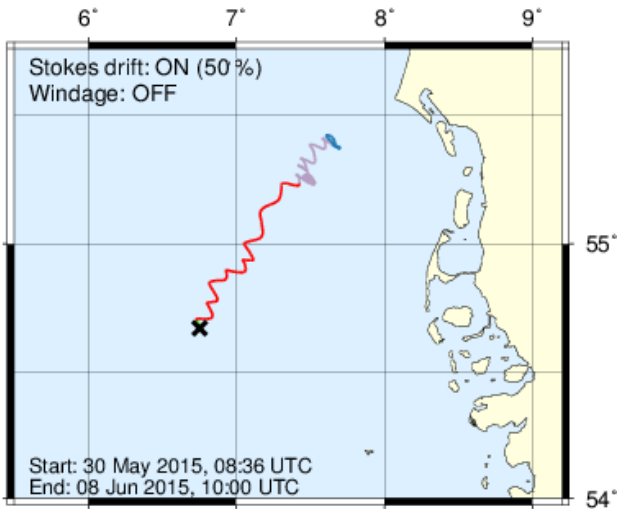

(f) BSHcmod+S, simulation drifter no. 9

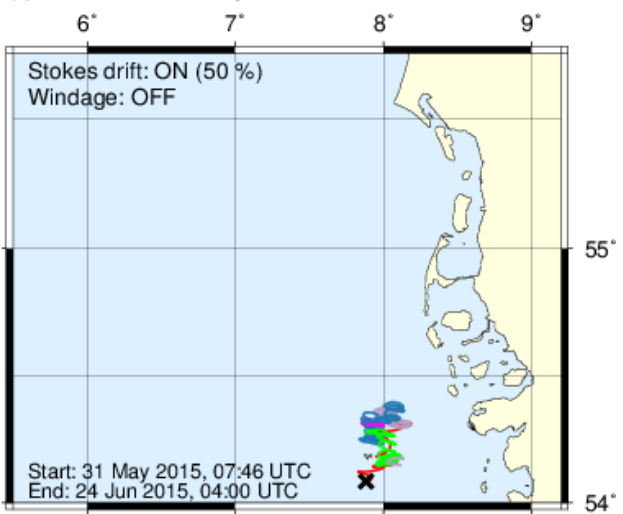

$-8-6-4-20244681012141618202224262830323436384042444648505254$

Days since 2015-05-27-13:00 UTC

Figure A3. Simulations based on BSHcmod top-layer currents plus $50 \%$ of surface Stokes drift from WAM (BSHcmod + S). Black crosses indicate locations where simulations were started. 


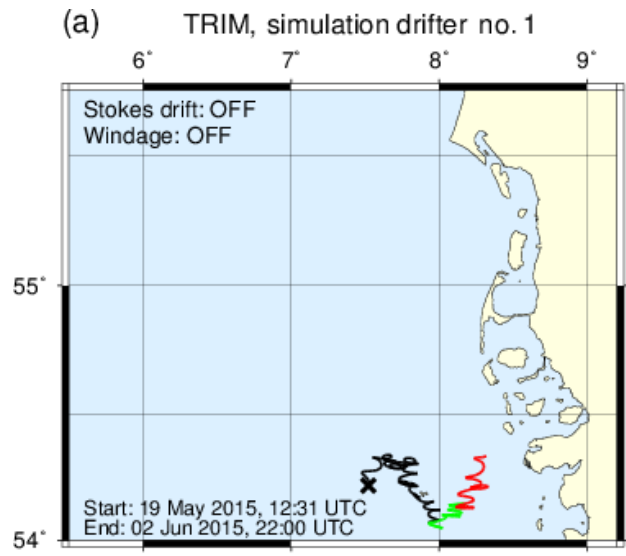

(b) TRIM, simulation drifter no. 5
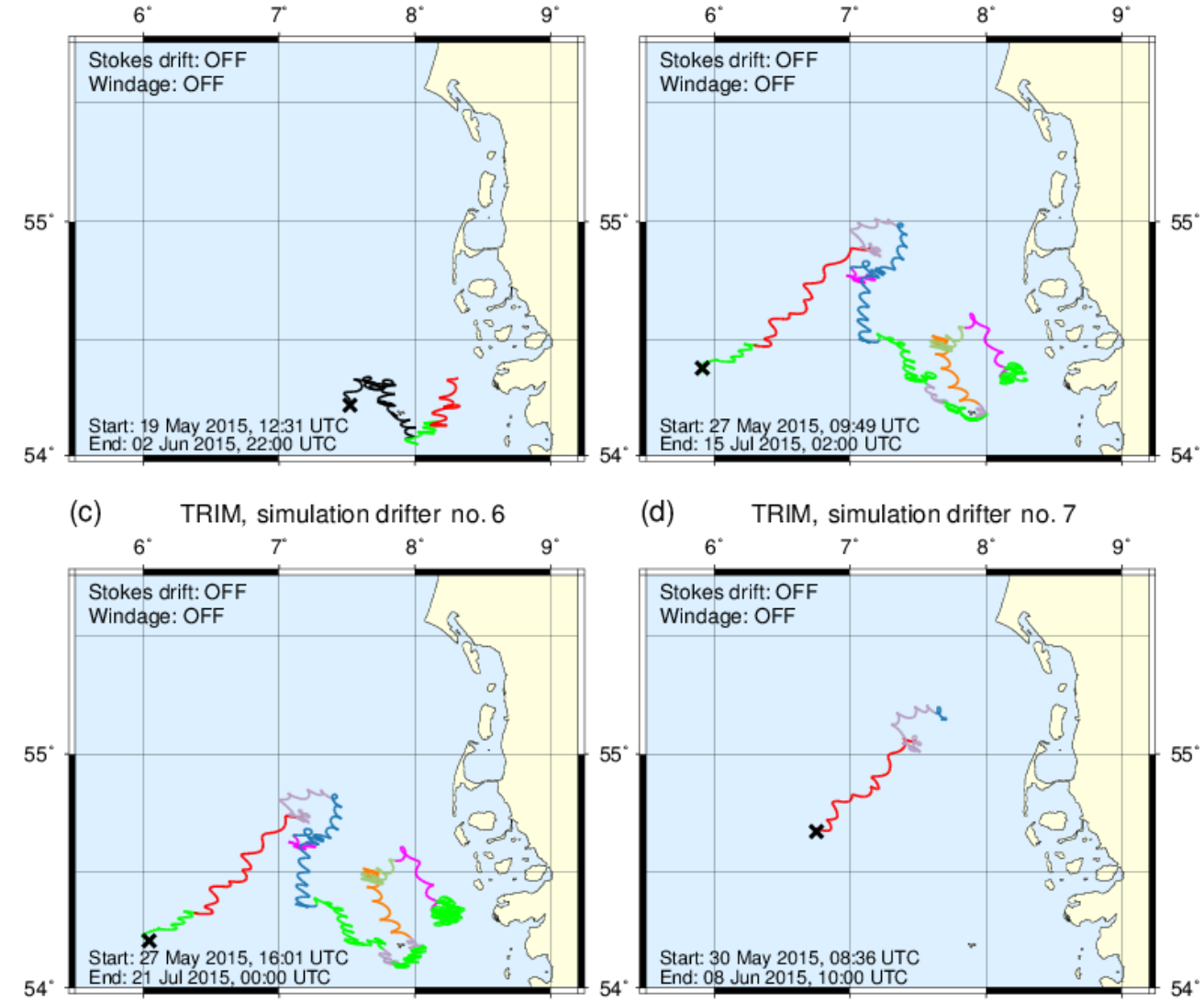

(d)

(d) TRIM, simulation drifter no. 7

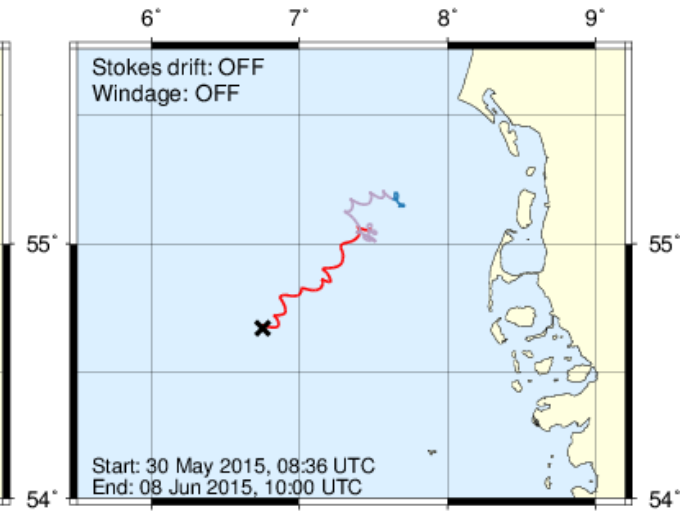

(e)

TRIM, simulation drifter no. 8

(f)
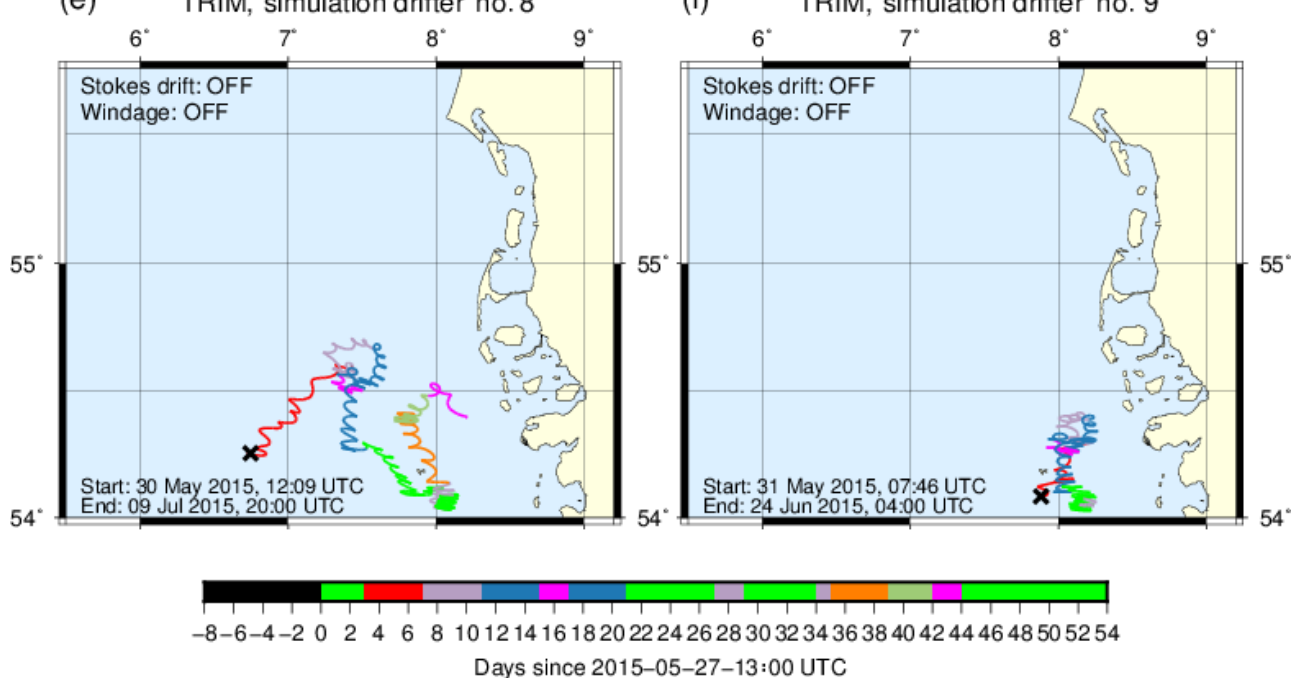

Figure A4. Simulations based on TRIM top-layer currents, disregarding extra effects of winds or waves. Black crosses indicate locations where simulations were started. 


\section{The Supplement related to this article is available online at https://doi.org/10.5194/os-13-799-2017-supplement.}

Author contributions. JH collected the field data. SM provided BSHcmod currents and her experience regarding performance of the operational model. HaK produced the TRIM simulations. FS preprocessed the raw drifter data for comparison with model data. HoK produced the residual current classification based on BSHcmod surface currents. NG conducted the WAM simulations. UC prepared the paper with contributions from all co-authors.

Competing interests. The authors declare that they have no conflict of interest.

Acknowledgements. This work was kindly supported through the Coastal Observing System for Northern and Arctic Seas (COSYNA). Wind observations at the Heligoland station were provided by the Deutscher Wetterdienst (DWD). Graphs were produced using the Generic Mapping Tools software (GMT) available from www.soest.hawaii.edu/gmt/. We appreciate valuable comments by Joakim Kjellsson and two anonymous reviewers that helped improve the presentation of our results.

The article processing charges for this open-access

publication were covered by a Research

Centre of the Helmholtz Association.

Edited by: Andreas Sterl

Reviewed by: Joakim Kjellsson and two anonymous referees

\section{References}

Ardhuin, F., Marié, L., Rascle, N., Forget, P., and Roland, A.: Observation and estimation of Lagrangian, Stokes and Eulerian currents induced by wind and waves at the sea surface, J. Phys. Oceanogr., 39, 2820-2838, 2009.

Barron, C. N., Smedstad, L. F., Dastugue, J. M., and Smedstad, O. M.: Evaluation of ocean models using observed and simulated drifter trajectories: Impact of sea surface height on synthetic profiles for data assimilation, J. Geophys. Res., 112, C07019, https://doi.org/10.1029/2006JC003982, 2007.

Beron-Vera, F. J. and LaCasce, J. H.: Statistics of simulated and observed pair separations in the Gulf of Mexico, J. Phys. Oceanogr., 46, 2183-2199, https://doi.org/10.1175/JPO-D-15-0127.1, 2016.

Brandt, G., Wehrmann, A., and Wirtz, K. W.: Rapid invasion of Crassostrea gigas into the German Wadden Sea dominated by larval supply, J. Sea Res., 59, 279-296, 2008.

Breivik, Ø. and Allen, A. A.: An operational search and rescue model for the Norwegian Sea and the North Sea, J. Marine Syst., 69, 99-113, 2008.

Breivik, Ø., Allen, A. A., Maisondieu, C., and Olagnon, M.: Advances in search and rescue at sea, Ocean Dynam., 63, 83-88, 2013.
Breivik, Ø., Bidlot, J.-R., and Janssen, P. A. E. M.: A Stokes drift approximation based on the Phillips spectrum, Ocean Model., 100, 49-56, 2016.

Broström, G., Carrasco, A., Hole, L. R., Dick, S., Janssen, F., Mattsson, J., and Berger, S.: Usefulness of high resolution coastal models for operational oil spill forecast: the "Full City" accident, Ocean Sci., 7, 805-820, https://doi.org/10.5194/os-7-805-2011, 2011.

Callies, U.: coastDat-2 Hydrodynamic Model TRIM-NP Principal Component Analysis Residual Currents, World Data Center for Climate, https://doi.org/10.1594/WDCC/TRIM-NP-2dPCA_ResCurr, 2016.

Callies, U., Plüß, A., Kappenberg, J., and Kapitza, H.: Particle tracking in the vicinity of Helgoland, North Sea: a model comparison, Ocean Dynam., 61, 2121-2139, 2011.

Callies, U., Gaslikova, L., Kapitza, H., and Scharfe, M.: German Bight residual current variability on a daily basis: principal components of multi-decadal barotropic simulations, Geo-Mar. Lett., 37, 151-162, https://doi.org/10.1007/s00367-016-0466-2, 2017.

Carrasco, R. and Horstmann, J.: German Bight surface drifter data from Heincke cruise HE 445, 2015, https://doi.org/10.1594/PANGAEA.874511, 2017.

Casulli, V. and Stelling, G.: Numerical simulation of 3D quasihydrostatic, free-surface flows, J. Hydraul. Eng., 124, 678-686, 1998.

Coelho, E. F., Hogan, P., Jacobs, G., Thoppil, P., Huntley, H. S., Haus, B. K., Lipphardt Jr., B. L., Kirwan Jr., A. D., Ryan, E. H., Olascoaga, J., Beron-Vera, F., Poje, A. C., Griffa, A., Özgökmen, T. M., Mariano, A. J., Novelli, G., Haza, A. C., Bogucki, D., Chen, S. S., Curcic, M., Iskandarani, M., Judt, F., Laxague, N., Renier, A. J. H. M., Valle-Levinson, A., and Wei, M.: Ocean current estimation using a Multi-Model Ensemble Kalman Filter during the Grand Lagrangian Deployment experiment (GLAD), Ocean Model., 87, 86-106, 2015.

Daewel, U., Schrum, C., and Gupta, A. K.: The predictive potential of early life stage individual-based models (IBMs): an example for Atlantic cod Gadus morhua in the North Sea, Mar. Ecol.Prog. Ser., 534, 199-219, 2015.

De Dominicis, M., Leuzzi, G., Pinardi, N., and Poulain, P.-M.: Eddy diffusivity derived from drifter data for dispersion model applications, Ocean Dynam., 62, 1381-1398, 2012.

Dick, S., Kleine, E., Müller-Navarra, S., Klein, H., and Komo, H.: The operational circulation model of BSH (BSHcmod), Model description and validation, Tech. Rep. 29/2001, BSH, 2001.

Dick, S., Kleine, E., and Janssen, F.: A new operational circulation model for the North Sea and Baltic Sea using a novel vertical co-oordinate setup and first results, in: Coastal to Global Operational Oceanography: Achievements and Challenges. Proceedings of the Fifth International Conference on EuroGOOS, 20-22 May 2008, Exeter, UK, edited by: Dalhin, H., Bell, M. J., Flemming, N. C., and Petersen, S. E., 2008.

Döös, K., Rupolo, V., and Brodeau, L.: Dispersion of surface drifters and model-simulated trajectories, Ocean Model., 39, 301-310, 2011.

Drivdal, M., Broström, G., and Christensen, K. H.: Waveinduced mixing and transport of buoyant particles: application to the Statfjord A oil spill, Ocean Sci., 10, 977-991, https://doi.org/10.5194/os-10-977-2014, 2014. 
Edwards, K. P., Werner, F. E., and Blanton, B. O.: Comparison of observed and modeled drifter trajectories in coastal regions: an improvement through adjustments for observed drifter slip and errors in wind fields, J. Atmos. Ocean. Tech., 23, 1614-1620, 2006.

Garraffo, Z. D., Mariano, A. J., Griffa, A., Veneziani, C., and Chassignet, E. P.: Lagrangian data in a high-resolution numerical simulation of the North Atlantic, J. Marine Syst., 29, 157-176, 2001.

Gästgifvars, M., Lauri, H., Sarkanen, A., Myrberg, K., Andrejev, O., and Ambjörn, C.: Modelling surface drifting of buoys during a rapidly-moving weather front in the Gulf of Finland, Baltic Sea, Estuar. Coast. Shelf S., 70, 567-576, 2006.

Geyer, B.: High-resolution atmospheric reconstruction for Europe 1948-2012: coastDat2, Earth Syst. Sci. Data, 6, 147-164, https://doi.org/10.5194/essd-6-147-2014, 2014.

Groll, N. and Weisse, R.: A multi-decadal wind-wave hindcast for the North Sea 19492014: coastDat2, Earth Syst. Sci. Data Discuss., https://doi.org/10.5194/essd-2017-36, in review, 2017.

Hasselmann, K.: Wave driven inertial oscillations, Geophys. Fluid Dyn., 1, 463-502, https://doi.org/10.1080/03091927009365783, 1970.

Havens, H., Luther, M. E., Meyers, S. D., and Heil, C. A.: Lagrangian particle tracking of a toxic dinoflagellate bloom within the Tampa Bay estuary, Mar. Pollut. Bull., 60, 2233-2241, 2010.

Horstmann, J., Schlick, T., Cysewski, M., Perthun, P., Stell, J., Boedewadt, J., Helzel, T., Seemann, J., Ziemer, F., Gurgel, K.-W., Meywerk, J., and Breitbach, G.: Sea surface current deduced from Doppler-shift of highfrequency radar backscatter, 2010-10-29 to 2016-12-31, https://doi.org/10.1594/PANGAEA.876437, 2017.

Hufnagl, M., Payne, M., Lacroix, G., Bolle, L. J., Daewel, U., Dickey-Collas, M., Gerkema, T., Huret, M., Janssen, F., Kreus, M., Pätsch, J., Pohlmann, T., Ruardij, P., Schrum, C., Skogen, M. D., Tiessen, M. C., Petitgas, P., van Beek, J. K., van der Veer, H. W., and Callies, U.: Variation that can be expected when using particle tracking models in connectivity studies, J. Sea Res., https://doi.org/10.1016/j.seares.2017.04.009, in press, 2017.

Huhn, F., von Kameke, A., Allen-Perkins, S., Montero, P., Venancio, A., and Pérez-Muñuzuri, V.: Horizontal Lagrangian transport in a tidal-driven estuary - Transport barriers attached to prominent coastal boundaries, Cont. Shelf Res., 39-40, 1-13, 2012.

Huntley, H. S., Lipphardt Jr., B. L., and Kirwan Jr., A. D.: Lagrangian predictability assessed in the East China Sea, Ocean Model., 36, 163-178, https://doi.org/10.1016/j.ocemod.2010.11.001, 2011.

Kapitza, H.: MOPS - a morphodynamical prediciton system on cluster computers, in: High performance computing for computational science, in: VECPAR 2008, 8th International Conference, Toulouse, France, June 2008, edited by: Laginha, J., Palma, M., Amestoy, P., Dayde, M., Mattoso, M., and Lopez, J., 63-68, Springer, Heidelberg, Berlin, New York, 2008.

Kistler, R., Kalnay, E., Collins, W., Saha, S., White, G., Woollen, J., Chelliah, M., Ebisuzaki, W., Kanamitsu, M., Kousky, V., van den Dool, H., Jenne, R., and Fiorino, M.: The NCEP-NCAR 50-year reanalysis: monthly means CD-ROM and documentation, B. Am. Meteorol. Soc., 82, 247-267, 2001.

Kjellsson, J. and Döös, K.: Surface drifters and model trajectories in the Baltic Sea, Boreal Environ. Res., 17, 447-459, 2012.
Komen, G. J., Cavaleri, L., Hasselmann, H., Hasselmann, S., and Janssen, P. A. E. M.: Dynamics and Modelling of Ocean Waves, Cambridge University Press, Cambridge, UK, 1996.

Koszalka, I., LaCasce, J. H., and Orvik, K. A.: Relative dispersion in the Nordic Seas, J. Mar. Res., 16, 431-447, 2009.

Li, Q., Fox-Kemper, B., Breivik, Ø., and Webb, A.: Statistical models of global Langmuir mixing, Ocean Model., 113, 95-114, 2017.

Lyard, F., Lefevre, F., Letellier, T., and Francis, O.: Modelling the global ocean tides: modern insights from FES2004, Ocean Dynam., 56, 394-415, 2006.

Mariano, A. J., Griffa, A., Özgökmen, T. M., and Zambianchi, E.: Lagrangian analysis and predictability of coastal and ocean dynamics 2000, J. Atmos. Ocean. Tech., 19, 1114-1126, 2002.

Maßmann, S., Janssen, F., Brüning, T., Kleine, E., Komo, H., Menzenhauer-Schumacher, I., and Dick, S.: An operational oil drift forecasting system for German coastal waters, Die Küste, 81, 255-271, 2014.

Nicolle, A., Dumas, F., Foveau, A., Foucher, E., and Thiébaut, E.: Modelling larval dispersal of the king scallop (Pecten maximus) in the English Channel: examples from the bay of Saint-Brieuc and the bay of Seine, Ocean Dynam., 63, 661-678, 2013.

Niiler, P. P., Johnson, W. R., and Baturin, N.: Surface Current and Lagrangian-drift Program, Tech. rep., U. S. Dept. of the Interior, Minerals Management Service, 1997.

Ohlmann, J. C., LaCasce, J. H., Washburn, L., Mariano, A. J., and Emery, B.: Relative dispersion observations and trajectory modelling in the Santa Barbara Channel, J. Geophys. Res., 117, 1-14, 2012.

Olascoaga, M. J., Beron-Vera, F. J., Haller, G., J.Triñanes, Iskandarani, M., Coelho, E. F., Haus, B. K., Huntley, H. S., Jacobs, G., Kirwan Jr., A. D., Lipphardt Jr., B. L., Özgökmen, T. M., Reniers, A. J. H. M., and Valle-Levinson, A.: Drifter motion in the Gulf of Mexico constrained by altimetric Lagrangian coherent structures, Geophys. Res. Lett., 40, 61716175, https://doi.org/10.1002/2013GL058624, 2013.

Pätsch, J., Burchard, H., Dieterich, C., Gräwe, U., Gröger, M., Mathis, M., Kapitza, H., Bersch, M., Moll, A., Pohlmann, T., Su, J., Ho-Hagemann, H. T. M., Schulz, A., Elizalde, A., and Eden, C.: An evaluation of the North Sea circulation in global and regional models relevant for ecosystem simulations, Ocean Model., 116, 70-95, https://doi.org/10.1016/j.ocemod.2017.06.005, 2017.

Peacock, T. and Haller, G.: Lagrangian coherent structures: The hidden skeleton of fluid flows, Phys. Today, 66, 41-47, 2013.

Perrie, W., Tang, C. L., Hu, Y., and DeTracy, B. M.: The impact of waves on surface currents, J. Phys. Oceanogr., 33, 2126-2140, 2003.

Polton, J. A., Lewis, D. M., and Belcher, S. E.: The role of wave-induced Coriolis-Stokes forcing on the wind-driven mixed layer, J. Phys. Oceanogr., 35, 444-457, 2005.

Port, A., Gurgel, K.-W., Staneva, J., Schulz-Stellenfleth, J., and Stanev, E. V.: Tidal and wind-driven surface currents in the German Bight: HFR observations versus model simulations, Ocean Dynam., 61, 1567-1585, 2011.

Poulain, P.-M., Gerin, R., Mauri, E., and Pennel, R.: Wind effects on drogued and undrogued drifters in the Eastern Mediterranean, J. Atmos. Ocean. Tech., 26, 1144-1156, 2009. 
Price, J. M., Reed, M., Howard, M. K., Johnson, W. R., Ji, Z.-G., Marshall, C. F., Guinasso Jr., N. L., and Rainey, G. B.: Preliminary assessment of an oil-spill trajectory model using satellitetracked, oil-spill-simulating drifters, Environ. Modell. Softw., 21, 258-270, 2006.

Puls, W., Pohlmann, T., and Sündermann, J.: Suspended particulate matter in the Southern North Sea: application of a numerical model to extend NERC North Sea Project data interpretation, Dt. hydrogr. Z., 49, 307-327, 1997.

Robins, P. E., Neill, S. P., Giménez, L., Jenkons, S. R., and Malham, S. K.: Physical and biological controls on larval dispersal and connectivity in a highly energetic shelf sea, Limnol. Oceanogr., 58, 505-524, 2013.

Röhrs, J. and Christensen, K. H.: Drift in the uppermost part of the ocean, Geophys. Res. Lett., 42, 10,349-10,356, https://doi.org/10.1002/2015GL066733, 2015.

Röhrs, J., Christensen, K. H., Hole, L. R., Broström, G., Drivdal, M., and Sundby, S.: Observation-based evaluation of surface wave effects on currents and trajectory forecasts, Ocean Dynam., 62, 1519-1533, 2012.

Sansón, L. Z., Pérez-Brunius, P., and Sheinbaum, J.: Surface relative dispersion in the Southwestern Gulf of Mexico, J. Phys. Oceanogr., 47, 387-403, https://doi.org/10.1175/JPO-D16-0105.1, 2017.

Schönfeld, W.: Numerical Simulation of the dispersion of artificial radionuclides in the English Channel and the North Sea, J. Marine Syst., 6, 529-544, 1995.

Schulz, J.-P., and Schättler, U.: Kurze Beschreibung des Lokal-Modells Europa COSMO-EU (LME) und seiner Datenbanken auf dem Datenserver des DWD, available at: https://www.dwd.de/SharedDocs/downloads/DE/ modelldokumentationen/nwv/cosmo_eu/cosmo_eu_dbbeschr_ 201406.pdf?_blob=publicationFile \&v=3 (last access: 12 September 2017), 2014.

Semedo, A., Vettor, R., Breivik, Ø., Sterl, A., Reistad, M., Soares, C. G., and Lima, D.: The wind sea and swell waves climate in the Nordic Seas, Ocean Dynam., 65, 223-240, https://doi.org/10.1007/s10236-014-0788-4, 2015.
Sentchev, A. and Korotenko, K.: Dispersion processes and transport pattern in the ROFI system of the Eastern English Channel derived from a particle-tracking model, Cont. Shelf Res., 25, 2294 2308, 2005.

Shadden, S. C., Lekien, F., Paduan, J. D., Chavez, F. P., and Marsden, J. E.: The correlation between surface drifters and coherent structures based on high-frequency radar data in Monterey Bay, Deep-Sea Res. Pt. II, 56, 161-172, 2009.

Smith, J. A.: Wave-current interactions in finite depth, J. Phys. Oceanogr., 36, 1403-1419, 2006.

Smith, S. and Banke, E.: Variation of the sea surface drag coefficient with wind speed, Q. J. Roy. Meteor. Soc., 101, 665-673, 1975.

Sobey, R. J. and Barker, C. H.: Wave-driven transport of surface oil, J. Coastal Res., 13, 490-496, 1997.

Staneva, J., Alari, V., Breivik, Ø., Bidlot, J.-R., and Mogensen, K.: Effects of wave-induced forcing on a circulation model of the North Sea, Ocean Dynam., 67, 81-101, https://doi.org/10.1007/s10236-016-1009-0, 2017.

Tang, C. L., Perrie, W., Jenkins, A. D., DeTracey, B. M., Hu, Y., Toulany, B., and Smith, P. C.: Observation and modeling of surface currents on the Grand Banks: A study of the wave effects on surface currents, J. Geophys. Res., 112, C10025, 1-16, 2007.

Ullman, D. S., O’Donnell, J., Kohut, J., Fake, T., and Allen, A.: Trajectory prediction using HF radar surface currents: Monte Carlo simulations of prediction uncertainties, J. Geophys. Res., 111, C12005, https://doi.org/10.1029/2006JC003715, 2006.

von Storch, H. and Zwiers, F. W.: Statistical Analysis in Climate Research, Cambridge University Press, Cambridge, UK, 1999.

von Storch, H., Langenberg, H., and Feser, F.: A spectral nudging technique for dynamical downscaling purposes, Mon. Weather Rev., 128, 3664-3673, 2000.

WAMDI-Group: The WAM model - a third generation ocean wave prediction model, J. Phys. Oceanogr., 18, 1775-1810, 1988. 